\title{
mRNA vaccination boosts cross-variant neutralizing antibodies elicited by SARS-CoV-2 infection
}

\author{
Leonidas Stamatatos ${ }^{1,2 *}$, Julie Czartoski', Yu-Hsin Wan', Leah J. Homad', Vanessa Rubin', Hayley Glantz', Moni \\ Neradilek $^{1}$, Emilie Seydoux' ${ }^{1}$ Madeleine F. Jennewein'1, Anna J. MacCamy', Junli Feng'1, Gregory Mize', Stephen \\ C. De Rosa ${ }^{1,3}$, Andrés Finzi ${ }^{4,5,6}$, Maria P. Lemos ${ }^{1}$, Kristen W. Cohen ${ }^{1}$, Zoe Moodie ${ }^{1}$, M. Juliana McElrath', ${ }^{1,7 *}$, \\ Andrew T. McGuire ${ }^{1,2,3 *}$ \\ ${ }^{1}$ Fred Hutchinson Cancer Research Center, Vaccine and Infectious Disease Division, Seattle, WA, USA. ${ }^{2}$ Department of Global Health, University of Washington, Seattle, WA, \\ USA. ${ }^{3}$ Department of Laboratory Medicine and Pathology, University of Washington, Seattle, WA, USA. ${ }^{4}$ Centre de Recherche du CHUM, Montréal, QC, Canada. \\ ${ }^{5}$ Département de Microbiologie, Infectiologie et Immunologie, Université de Montréal, Montreal, QC, Canada. ${ }^{6}$ Department of Microbiology and Immunology, McGill \\ University, Montreal, QC, Canada. ${ }^{7}$ Department of Medicine, University of Washington, Seattle, WA, USA. \\ *Corresponding author. Email: amcguire@fredhutch.org (A.T.M.); Istamata@fredhutch.org (L.S.); jmcelrat@fredhutch.org (M.J.M.)
}

Emerging SARS-CoV-2 variants have raised concerns about resistance to neutralizing antibodies elicited by previous infection or vaccination. We examined whether sera from recovered and naïve donors collected prior to, and following immunizations with existing mRNA vaccines, could neutralize the Wuhan-Hu-1 and B.1.351 variants. Pre-vaccination sera from recovered donors neutralized Wuhan-Hu-1 and sporadically neutralized B.1.351, but a single immunization boosted neutralizing titers against all variants and SARSCoV-1 by up to 1000 -fold. Neutralization was due to antibodies targeting the receptor binding domain and was not boosted by a second immunization. Immunization of naïve donors also elicited cross-neutralizing responses, but at lower titers. Our study highlights the importance of vaccinating both uninfected and previously infected persons to elicit cross-variant neutralizing antibodies.

The SARS-CoV-2 betacoronavirus first emerged in the Hubei Province of China in late 2019 and has since infected over 115 million people and caused over 2.5 million deaths in 192 countries (1-3).

Infection is mediated by the viral spike protein (S) which is comprised of an $\mathrm{S} 1$ domain that contains a $\mathrm{N}$-terminal domain (NTD), a C-terminal domain (CTD), and a receptor binding domain (RBD) which mediates attachment to the entry receptor angiotensin converting enzyme 2 (ACE2), and an S2 domain that contains the fusion machinery (4-8).

Pre-existing immunity to SARS-CoV-2 is associated with protection against re-infection in humans $(9-11)$ and in nonhuman primates $(12,13)$. Although the correlates of protection in humans against repeat infection or following vaccination have not been firmly established, neutralizing antibodies (nAbs) are thought to be an important component of a protective immune response against SARS-CoV-2 $(14,15)$. In support of this, passive transfer of nAbs limits respiratory tract infection and protects against infection in animal models (16-20) and may contribute to protection against infection in humans (9). SARS-CoV-2 infection rapidly elicits nAbs (16, 21-24) that decline, but remain detectable over several months (25-29).

The majority of serum neutralizing antibody responses elicited during natural infection are directed at the receptor binding domain (RBD) $(21,23,30,31)$. Numerous neutralizing anti-RBD monoclonal antibodies (mAbs) have been characterized, the most potent of which block the RBD-ACE2 interaction $(16,17,22-24,32-37)$. Neutralizing against other region of the viral spike have also been identified $(24,33,38-$ 42).

Two mRNA-based vaccines (Pfizer/BioNTech BNT162b2, and Moderna mRNA-1273) have received emergency use authorization in several countries. Both encode a stabilized ectodomain version of the $\mathrm{S}$ protein derived from the WuhanHu-1 variant isolated in December 2019 (43), show greater than $94 \%$ efficacy at preventing COVID-19 illness (44-47), and elicit nAbs $(48,49)$.

Due to the high global burden of SARS-CoV-2 transmission, viral evolution is occurring. Recently, viral variants of concern have emerged in the United Kingdom (B.1.1.7), South Africa (B.1.351), and Brazil (P.1) that harbor specific mutations in their $\mathrm{S}$ proteins that may be associated with increased transmissibility (50-55).

Of particular concern are mutations found in the B.1.351 lineage, which is defined by the D80A and D215G in the Nterminal domain (NTD), and the K417N, E484K, N501Y mutations in the RBD and the D614G mutation in S2 $(52,56)$. An A701V mutation in S2 is also observed at high frequencies, while deletions in 242-244 and R246I and L18F mutations in the NTD are present at lower frequencies (52).

The B.1.1.7, B.1.351, and P.1 lineages all harbor a N501Y mutation in the RBD which increases the affinity for the ACE2 receptor $(57,58)$, and a D614G mutation which 
increases virion spike density, infectivity and transmissibility $(59,60)$. The B.1.351 and P.1 lineages also share the E484K mutations in the RBD and both variants are mutated at 417 (K417T in P.1).

Mutations found in emergent $\mathrm{S}$ variants decrease sensitivity to neutralization by mAbs, convalescent plasma, and sera from vaccinated individuals $(27,37,58,61-70)$. As a result, there is concern that these and other emerging variants can evade neutralizing antibody responses generated during infection with variants circulating earlier in the pandemic and also from neutralizing antibody responses elicited by vaccines based on the spike protein of the Wuhan-Hu-1 variant. Indeed, there is concern that these mutations are responsible for reduced efficacy observed in ongoing trials of SARS-CoV2 vaccines in South Africa (71, 72).

Here, we evaluated the neutralization susceptibility of spike variants harboring lineage-defining and prevalent B.1.351 mutations to sera from 15 donors with previously confirmed SARS-CoV-2 infection (herein referred to as previously infected donors or PIDs), that were collected prior to, and following one or two immunizations with either mRNA vaccine, or from 13 uninfected donors who received two doses of the above vaccines (herein called naïve donors or NDs; tables S1 and S2), as well as anti-spike mAbs isolated from infected but not vaccinated patients.

Antibody neutralization experiments were performed with pseudoviruses expressing either the full-length WuhanHu-1 S, or either of two versions of the B.1.351 lineage $S$, one herein referred to as B.1.351 containing the lineage-defining S mutations D80A, D215G, K417N, E484K, N501Y and D614G mutations and the A701V mutation that is highly prevalent in this lineage, and a second variant that also includes a $\triangle 242$ 243 deletion (B.1.351 $\triangle 242-243)$. The viral stocks were appropriately diluted to achieve comparable entry levels during the neutralization experiments (fig. S1).

We first evaluated the neutralizing potency of several mAbs isolated from non-vaccinated patients infected early in the pandemic, which target different epitopes: three against the RBD (CV30, CV3-1 and CV2-75) and one against the NTD (CV1) (fig. S2). CV30 is a member of the VH3-53 class of antibodies that bind to the receptor binding motif (RBM) $(22,32$, 73-78). It makes direct contact with the K417 and N501 residues in the RBM that are mutated in the B.1.351 and P.1 lineages, but unlike other known VH3-53 mAbs it does not contact E484 (78). The neutralization potency of this $\mathrm{mAb}$ was 10-fold weaker toward both B.1.351 variants (Fig. 1A). Similarly, the non-VH3-53 mAb CV3-1 was 3-4-fold less potent against the B.1.351 variants (Fig. 1B), while CV2-75 was modestly less effective (Fig. 1C). In contrast, the anti-NTD CV1 mAb was unable to neutralize either B.1.351 variant (Fig. 1D). As expected, the control anti-EBV mAb AMMO1 was non-neutralizing (79) (Fig. 1E). Collectively, these data indicate that the B.1.351 variants tested here are more resistant to neutralization by mAbs isolated from subjects infected by viral variants from early in the pandemic. We therefore examined whether the B.1.351 variants are resistant to neutralizing antibody responses elicited by the Pfizer/BioNTech or Moderna mRNA vaccines, in PIDs and NDs.

The RBD-specific IgG, IgM and IgA binding responses to the RBD from the Wuhan-Hu1 variant were measured before (average, 202 days post symptom onset; table S1), and 5-29 days (table S1) after the first and second immunizations in the PIDs, and 6-28 days after the second immunization in the NDs. Three PIDs experienced asymptomatic SARS-CoV-2 infection (donors D, L, and M; table S1) two of whom, L and M, did not have detectable anti-RBD IgG antibodies prior to immunization, while the third, D, had low but detectable serum anti-RBD IgG antibody titers (Fig. 2A). In the 13 PIDs with RBD-specific IgG antibodies prior to vaccination, a single dose of either vaccine boosted these titers by $~ 500$-fold (Fig. $2 \mathrm{~A})$. Across all PIDs there was a 200 -fold increase in median RBD-specific IgA titers post-vaccination (Fig. 2B). Overall, in PIDs, a single vaccine dose elicited 4.5-fold higher IgG, and 7.7-fold higher IgA titers than two vaccinations in NDs. RBDspecific IgM titers were generally lower and were not significantly boosted in response to vaccination in both PIDs and NDs (Fig. 2C). In PIDs, a concomitant increase in RBD- (Fig. 2D) and S-specific $\mathrm{IgG}^{+}$(Fig. 2E) memory B cell frequencies took place after vaccination. The two PIDs that lacked RBDspecific IgG titers prior to immunization (donors $\mathrm{L}$ and $\mathrm{M}$ ) also lacked RBD-specific IgG+ memory B cells (Fig. 2D) and had lower frequencies of S-specific $\mathrm{IgG}^{+}$memory B cells after vaccination. Consistent with the serology data, an increase in the frequency of $\mathrm{IgA}^{+}$(Fig. 2F) but not $\mathrm{IgM}^{+}$spike-specific memory B cells was observed (fig. S3). Vaccination also induced S-specific CD4 ${ }^{+}$T-cell responses (Fig. 2G).

Sera from 12 of 15 PIDs sampled before vaccination neutralized the Wuhan-Hu-1 SARS-CoV-2 variant (Fig. 3A and fig. S4). The non-neutralizing sera were from the three asymptomatic PIDs who had low or undetectable anti-RBD IgG titers (Fig. 3A, dashed lines, and fig. S4), while pre-vaccine sera from the NDs were also non-neutralizing (fig. S5). Consistent with the observed increase in binding antibodies following a single immunization in PIDs with pre-existing RBD-specific IgG titers, the median half-maximal neutralizing titers $\left(\mathrm{ID}_{50}\right)$ were boosted approximately 1000-fold after the first dose, while the second dose had no effect (Fig. 3A). In the two PIDs lacking RBD-specific IgG titers prior to vaccination, the first vaccine dose elicited lower neutralizing titers $\left(\mathrm{ID}_{50}=\sim 100\right.$ in donor $\mathrm{L}$ and $\sim 1,100$ in donor M; Fig. 3A). In the NDs, two doses of the vaccine elicited $\mathrm{ID}_{50}$ titers that were $\sim 10$ - and 5fold lower than those elicited by one or two doses in the PIDs, respectively (Fig. 3A and fig. S6). Collectively, these data indicate that in PIDs who generate adequate immunological 
memory to the RBD, a single vaccine dose elicits an anamnestic response resulting in RBD-binding and neutralizing antibody responses that are superior to a two-dose regimen in uninfected donors. A similar boost in binding and/or vaccine-matched neutralizing titers has been observed in PIDs who received a single $\mathrm{mRNA}$ vaccine dose in two recent studies $(80,81)$.

We next evaluated the ability of sera collected before and after immunization in NDs and PIDs to neutralize the more resistant B.1.351 and B.1.351- $\triangle 242-243$ pseudoviruses. These variants are $0.5 \%$ and $0.7 \%$ divergent from the Wuhan-Hu-1 variant. We also included SARS-CoV-1 pseudoviruses in this analysis, as a representative variant that is even more dissimilar to the vaccine. SARS-CoV-1 and SARS-CoV-2 are 24\%, $26 \%$ and $50 \%$ divergent in the overall S protein, RBD and receptor binding motif, respectively (82). As a consequence, several mAbs that potently neutralize SARS CoV-2 fail to bind SARS-CoV-1 (16, 22-24).

Prior to vaccination, 5 of 15 sera from PIDs neutralized B.1.351 and only three had $\mathrm{ID}_{50}$ titers above 100 (Fig. 3, B and E, and fig. S4), 7 of 15 neutralized B.1.351 $\triangle 242-243$, and only one had titers above 100 (Fig. 3, C and E, and fig. S4). Only two pre-vaccine PID sera achieved $80 \%$ neutralization of B.1.351, and only one achieved $80 \%$ neutralization of B.1.351$\triangle 242-243$ (fig. S7A). The median ID $_{50}$ of the pre-vaccine sera against Wuhan Hu-1 was significantly higher than against B.1.351 or B.1.351- $\triangle 242-243$ (Fig. 3E). Consistent with the high level of sequence disparity, sera from only one PID showed very weak neutralizing activity toward SARS-CoV-1 prior to vaccination (Fig. 3, D and E, and fig. S7).

A single immunization boosted the $\mathrm{nAb}$ titers against all three SARS-CoV-2 variants and SARS-CoV-1 in 13 of 15 PIDs (Fig. 3, A to D); however, the median ID $_{50}$ titers were $\sim 3$-fold lower against B.1.351, 10-fold lower against B.1.351- $\triangle 242$ 243, and 100-fold lower against SARS-CoV-1 than Wuhan-Hu1 (Fig. 3E). A single immunization did not elicit nAbs against the B.1.351 variants or SARS CoV-1 in the two asymptomatic donors who lacked RBD-specific IgG memory (donor L and M; Fig. 3, A to D, and Fig. 3E, open circles). The median $\mathrm{ID}_{80}$ values were also lower for the B.1.351 and B.1.351- $\triangle 242-243$ as compared to Wuhan-Hu-1 (fig. S7A).

The neutralizing titers elicited by a single immunization in PIDs were significantly higher than those elicited by two immunizations in NDs against all pseudoviruses tested; 10fold higher against Wuhan-Hu-1 (Fig. 3A), 20-fold higher against B.1.351 (Fig. 3B), 30-fold higher against B.1.351- $\triangle 242$ 243 (Fig. 3C), and 7-fold higher against SARS-CoV-1 (Fig. 3D). Only 8 of 13 vaccinated NDs were able to achieve $80 \%$ neutralization of B.1.351- $\triangle 242-243$, and none could achieve $80 \%$ neutralization of SARS-CoV-1 (fig. S7B).

The B.1.351 and B.1.351- $\triangle 242-243$ variants contain three RBD mutations that affect the neutralization potency of anti-
RBD mAbs (Fig. 1). Moreover, pre-existing anti-RBD IgG memory appears to be important for a robust recall response to vaccination. To determine the relative contribution of antiRBD antibodies to serum neutralization, we depleted RBDspecific antibodies from the sera of ten PIDs following one vaccination and from nine NDs after two vaccinations. This approach efficiently removed RBD-specific (Fig. 4, A and C) but not anti-S2P specific antibodies from sera, as measured by ELISA (Fig. 4, B and D). This depletion abrogated serum neutralization of Wuhan-Hu-1 virus (Fig. 4, C and F), suggesting that the majority of neutralizing antibodies elicited or boosted by vaccination target this subdomain.

The above results indicate that in NDs, two doses of either the Pfizer/BioNTech or Moderna vaccines elicited nAb titers against the vaccine matched Wuhan-Hu-1, lower titers against B.1.351 and even lower titers against B.1.351- $\triangle 242$ 243. Reduced sensitivity to vaccine-elicited nAbs has been reported for other B.1.351 variants $(66,83,84)$.

Similarly, sera from PIDs who experienced symptomatic SARS-CoV-2 infection and who had detectable anti-RBD IgG titers prior to vaccination displayed generally weak $\mathrm{nAb}$ titers against Wuhan-Hu-1 at one to nine months post-infection and lower, or non-existent titers against the B.1.351 variants, in agreement with another report (69). However, provided RBD-specific $\mathrm{IgG}^{+}$memory $\mathrm{B}$ cell and antibody responses were generated during infection, a single immunization with either mRNA vaccine elicited a robust recall response that boosted the autologous neutralizing titers by approximately 1000-fold and importantly, these antibody responses crossneutralized the B.1.351 variants, but at lower titers. In the majority of previously infected vaccinees, the anti- B.1.351- $\triangle 242$ 243 neutralizing titers were comparable to those against the vaccine-matched Wuhan-Hu-1 in uninfected vaccinees. This is notable as these titers were associated with $95 \%$ protection from COVID-19 in phase 3 trials $(44,46,48,49)$. Moreover, vaccine-elicited antibody responses also neutralized SARSCoV-1, but with much lower potencies. Collectively, our data suggest that the two mRNA vaccines that are based on the Wuhan-Hu-1 variant can elicit and/or boost neutralizing antibody responses, but that their potency is reduced against divergent variants.

Here, we show that the cross-neutralizing antibody responses generated after immunization in previously infected subjects are due to anti-RBD antibodies. Combined with the observation that the vaccines elicited neutralizing antibody responses that are less potent against the B.1.351 variant with the 242-243 deletion in the NTD suggests that NTD mutations can modulate the sensitivity of emerging variants to anti-RBD neutralizing antibodies. In contrast, the NTD region itself, which appears to tolerate antigenic variation in SARS-CoV-2 and other coronaviruses $(50,52,55,85)$, does not appear to be the target of cross-neutralizing antibodies 
elicited by infection or vaccination. We note that there are other less-frequent mutations associated with this lineage, such as L18F, $\triangle 244$, L244H, and R246I that were not examined here which may further increase resistance to vaccineelicited antibodies. In this study, a pseudovirus assay was used to measure neutralizing antibodies. Several studies have now shown that authentic virus and pseudovirus neutralization correlate quire well $(16,86,87)$. Although the absolute sensitivity of the authentic and pseudovirus assays may differ, we anticipate that the relative differences we report here will not vary between the two.

Although the correlates of protection for SARS CoV-2 vaccines have not been established, studies in non-human primates indicate that even low titers of neutralizing antibodies are sufficient to prevent experimental SARS-CoV-2 infection, particularly if CD8+ T-cell responses are mounted (18). Our study suggests that most previously infected subjects will benefit from a single immunization with either the Pfizer/BioNTech or Moderna vaccines as it will lead to significant increases in serum neutralizing antibody responses against vaccine-matched and emerging variants. The observation that a second dose administered three to four weeks following the first in previously infected donors who have clear evidence of RBD-directed immunological memory prior to vaccination did not further boost neutralizing titers, suggests that the second dose of an mRNA vaccine could be delayed in some persons who have previously been infected with SARSCoV-2. Longitudinal monitoring of the neutralizing antibody titers before and following the first dose should be used to determine the necessity, or optimal timing of the second dose in the context of previous infection.

\section{REFERENCES AND NOTES}

1. E. Dong, H. Du, L. Gardner, An interactive web-based dashboard to track COVID-19 in real time. Lancet Infect. Dis. 20, 533-534 (2020). doi:10.1016/S14733099(20)30120-1 Medline

2. P. Zhou, X.-L. Yang, X.-G. Wang, B. Hu, L. Zhang, W. Zhang, H.-R. Si, Y. Zhu, B. Li, C.L. Huang, H.-D. Chen, J. Chen, Y. Luo, H. Guo, R.-D. Jiang, M.-Q. Liu, Y. Chen, X.-R. Shen, X. Wang, X.-S. Zheng, K. Zhao, Q.-J. Chen, F. Deng, L.-L. Liu, B. Yan, F.-X. Zhan, Y.-Y. Wang, G.-F. Xiao, Z.-L. Shi, A pneumonia outbreak associated with a new coronavirus of probable bat origin. Nature 579, 270-273 (2020). doi:10.1038/s41586-020-2012-7 Medline

3. N. Zhu, D. Zhang, W. Wang, X. Li, B. Yang, J. Song, X. Zhao, B. Huang, W. Shi, R. Lu, P. Niu, F. Zhan, X. Ma, D. Wang, W. Xu, G. Wu, G. F. Gao, W. Tan, China Novel Coronavirus Investigating and Research Team, A Novel Coronavirus from Patients with Pneumonia in China, 2019. N. Engl. J. Med. 382, 727-733 (2020). doi:10.1056/NEJMoa2001017 Medline

4. A. C. Walls, Y.-J. Park, M. A. Tortorici, A. Wall, A. T. McGuire, D. Veesler, Structure, Function, and Antigenicity of the SARS-CoV-2 Spike Glycoprotein. Cell 181, 281292.e6 (2020). doi:10.1016/i.cell.2020.02.058 Medline

5. M. Hoffmann, H. Kleine-Weber, S. Schroeder, N. Krüger, T. Herrler, S. Erichsen, T. S. Schiergens, G. Herrler, N.-H. Wu, A. Nitsche, M. A. Müller, C. Drosten, S. Pöhlmann, SARS-CoV-2 Cell Entry Depends on ACE2 and TMPRSS2 and Is Blocked by a Clinically Proven Protease Inhibitor. Cell 181, 271-280.e8 (2020). doi:10.1016/i.cell.2020.02.052 Medline

6. M. Letko, A. Marzi, V. Munster, Functional assessment of cell entry and receptor usage for SARS-CoV-2 and other lineage B betacoronaviruses. Nat. Microbiol. 5 , 562-569 (2020). doi:10.1038/s41564-020-0688-y Medline
7. X. Ou, Y. Liu, X. Lei, P. Li, D. Mi, L. Ren, L. Guo, R. Guo, T. Chen, J. Hu, Z. Xiang, Z. Mu, X. Chen, J. Chen, K. Hu, Q. Jin, J. Wang, Z. Qian, Characterization of spike glycoprotein of SARS-CoV-2 on virus entry and its immune cross-reactivity with SARS-CoV. Nat. Commun. 11, 1620 (2020). doi:10.1038/s41467-020-15562-9 Medline

8. D. Wrapp, N. Wang, K. S. Corbett, J. A. Goldsmith, C.-L. Hsieh, O. Abiona, B. S. Graham, J. S. McLellan, Cryo-EM structure of the 2019-nCoV spike in the prefusion conformation. Science 367, 1260-1263 (2020). doi:10.1126/science.abb2507 Medline

9. A. Addetia, K. H. D. Crawford, A. Dingens, H. Zhu, P. Roychoudhury, M.-L. Huang, K. R. Jerome, J. D. Bloom, A. L. Greninger, Neutralizing Antibodies Correlate with Protection from SARS-CoV-2 in Humans during a Fishery Vessel Outbreak with a High Attack Rate. J. Clin. Microbiol. 58, e02107-20 (2020). doi:10.1128/JCM.02107-20 Medline

10. I. W. Pray, S. N. Gibbons-Burgener, A. Z. Rosenberg, D. Cole, S. Borenstein, A. Bateman, E. Pevzner, R. P. Westergaard, COVID-19 Outbreak at an Overnight Summer School Retreat - Wisconsin, July-August 2020. MMWR Morb. Mortal. Wkly. Rep. 69, 1600-1604 (2020). doi:10.15585/mmwr.mm6943a4 Medline

11. S. F. Lumley, D. O'Donnell, N. E. Stoesser, P. C. Matthews, A. Howarth, S. B. Hatch, B. D. Marsden, S. Cox, T. James, F. Warren, L. J. Peck, T. G. Ritter, Z. de Toledo, L. Warren, D. Axten, R. J. Cornall, E. Y. Jones, D. I. Stuart, G. Screaton, D. Ebner, S. Hoosdally, M. Chand, D. W. Crook, A.-M. O'Donnell, C. P. Conlon, K. B. Pouwels, A. S. Walker, T. E. A. Peto, S. Hopkins, T. M. Walker, K. Jeffery, D. W. Eyre, Oxford University Hospitals Staff Testing Group, Antibody Status and Incidence of SARSCoV-2 Infection in Health Care Workers. N. Engl. J. Med. 384, 533-540 (2021). doi:10.1056/NEJMoa2034545 Medline

12. A. Chandrashekar, J. Liu, A. J. Martinot, K. McMahan, N. B. Mercado, L. Peter, L. H. Tostanoski, J. Yu, Z. Maliga, M. Nekorchuk, K. Busman-Sahay, M. Terry, L. M. Wrijil, S. Ducat, D. R. Martinez, C. Atyeo, S. Fischinger, J. S. Burke, M. D. Slein, L. Pessaint, A. Van Ry, J. Greenhouse, T. Taylor, K. Blade, A. Cook, B. Finneyfrock, R. Brown, E. Teow, J. Velasco, R. Zahn, F. Wegmann, P. Abbink, E. A. Bondzie, G. Dagotto, M. S. Gebre, X. He, C. Jacob-Dolan, N. Kordana, Z. Li, M. A. Lifton, S. H. Mahrokhian, L. F. Maxfield, R. Nityanandam, J. P. Nkolola, A. G. Schmidt, A. D. Miller, R. S. Baric, G. Alter, P. K. Sorger, J. D. Estes, H. Andersen, M. G. Lewis, D. H. Barouch, SARS-CoV-2 infection protects against rechallenge in rhesus macaques. Science 369, 812-817 (2020). doi:10.1126/science.abc4776 Medline

13. W. Deng, L. Bao, J. Liu, C. Xiao, J. Liu, J. Xue, Q. Lv, F. Qi, H. Gao, P. Yu, Y. Xu, Y. Qu, F. Li, Z. Xiang, H. Yu, S. Gong, M. Liu, G. Wang, S. Wang, Z. Song, Y. Liu, W. Zhao, Y. Han, L. Zhao, X. Liu, Q. Wei, C. Qin, Primary exposure to SARS-CoV-2 protects against reinfection in rhesus macaques. Science 369, 818-823 (2020). doi:10.1126/science. abc5343 Medline

14. D. S. Stephens, M. J. McElrath, COVID-19 and the Path to Immunity. JAMA 324 , 1279-1281 (2020). doi:10.1001/jama.2020.16656 Medline

15. K. P. O'Callaghan, A. M. Blatz, P. A. Offit, Developing a SARS-CoV-2 Vaccine at Warp Speed. JAMA 324, 437-438 (2020). doi:10.1001/jama.2020.12190 Medline

16. T. F. Rogers, F. Zhao, D. Huang, N. Beutler, A. Burns, W. T. He, O. Limbo, C. Smith, G. Song, J. Woehl, L. Yang, R. K. Abbott, S. Callaghan, E. Garcia, J. Hurtado, M. Parren, L. Peng, S. Ramirez, J. Ricketts, M. J. Ricciardi, S. A. Rawlings, N. C. Wu, M. Yuan, D. M. Smith, D. Nemazee, J. R. Teijaro, J. E. Voss, I. A. Wilson, R. Andrabi, B. Briney, E. Landais, D. Sok, J. G. Jardine, D. R. Burton, Isolation of potent SARSCoV-2 neutralizing antibodies and protection from disease in a small animal model. Science 369, 956-963 (2020). doi:10.1126/science.abc7520 Medline

17. S. J. Zost, P. Gilchuk, J. B. Case, E. Binshtein, R. E. Chen, J. P. Nkolola, A. Schäfer, J. X. Reidy, A. Trivette, R. S. Nargi, R. E. Sutton, N. Suryadevara, D. R. Martinez, L. E. Williamson, E. C. Chen, T. Jones, S. Day, L. Myers, A. O. Hassan, N. M. Kafai, E. S. Winkler, J. M. Fox, S. Shrihari, B. K. Mueller, J. Meiler, A. Chandrashekar, N. B. Mercado, J. J. Steinhardt, K. Ren, Y.-M. Loo, N. L. Kallewaard, B. T. McCune, S. P. Keeler, M. J. Holtzman, D. H. Barouch, L. E. Gralinski, R. S. Baric, L. B. Thackray, M. S. Diamond, R. H. Carnahan, J. E. Crowe Jr., Potently neutralizing and protective human antibodies against SARS-CoV-2. Nature 584, 443-449 (2020). doi:10.1038/s41586-020-2548-6 Medline

18. K. McMahan, J. Yu, N. B. Mercado, C. Loos, L. H. Tostanoski, A. Chandrashekar, J. Liu, L. Peter, C. Atyeo, A. Zhu, E. A. Bondzie, G. Dagotto, M. S. Gebre, C. JacobDolan, Z. Li, F. Nampanya, S. Patel, L. Pessaint, A. Van Ry, K. Blade, J. YalleyOgunro, M. Cabus, R. Brown, A. Cook, E. Teow, H. Andersen, M. G. Lewis, D. A. 
Lauffenburger, G. Alter, D. H. Barouch, Correlates of protection against SARSCoV-2 in rhesus macaques. Nature 590, 630-634 (2021). doi:10.1038/s41586020-03041-6 Medline

19. A. Baum, D. Ajithdoss, R. Copin, A. Zhou, K. Lanza, N. Negron, M. Ni, Y. Wei, K. Mohammadi, B. Musser, G. S. Atwal, A. Oyejide, Y. Goez-Gazi, J. Dutton, E. Clemmons, H. M. Staples, C. Bartley, B. Klaffke, K. Alfson, M. Gazi, O. Gonzalez, E. Dick Jr., R. Carrion Jr., L. Pessaint, M. Porto, A. Cook, R. Brown, V. Ali, J. Greenhouse, T. Taylor, H. Andersen, M. G. Lewis, N. Stahl, A. J. Murphy, G. D. Yancopoulos, C. A. Kyratsous, REGN-COV2 antibodies prevent and treat SARSCoV-2 infection in rhesus macaques and hamsters. Science 370, 1110-1115 (2020). doi:10.1126/science.abe2402 Medline

20. A. Schäfer, F. Muecksch, J. C. C. Lorenzi, S. R. Leist, M. Cipolla, S. Bournazos, F. Schmidt, R. M. Maison, A. Gazumyan, D. R. Martinez, R. S. Baric, D. F. Robbiani, T. Hatziioannou, J. V. Ravetch, P. D. Bieniasz, R. A. Bowen, M. C. Nussenzweig, T. P. Sheahan, Antibody potency, effector function, and combinations in protection and therapy for SARS-CoV-2 infection in vivo. J. Exp. Med. 218, e20201993 (2021). doi:10.1084/jem.20201993 Medline

21. M. S. Suthar, M. G. Zimmerman, R. C. Kauffman, G. Mantus, S. L. Linderman, W. H. Hudson, A. Vanderheiden, L. Nyhoff, C. W. Davis, O. Adekunle, M. Affer, M. Sherman, S. Reynolds, H. P. Verkerke, D. N. Alter, J. Guarner, J. Bryksin, M. C. Horwath, C. M. Arthur, N. Saakadze, G. H. Smith, S. Edupuganti, E. M. Scherer, K. Hellmeister, A. Cheng, J. A. Morales, A. S. Neish, S. R. Stowell, F. Frank, E. Ortlund, E. J. Anderson, V. D. Menachery, N. Rouphael, A. K. Mehta, D. S. Stephens, R. Ahmed, J. D. Roback, J. Wrammert, Rapid Generation of Neutralizing Antibody Responses in COVID-19 Patients. Cell Rep. Med. 1, 100040 (2020). doi:10.1016/j.xcrm.2020.100040 Medline

22. E. Seydoux, L. J. Homad, A. J. MacCamy, K. R. Parks, N. K. Hurlburt, M. F. Jennewein, N. R. Akins, A. B. Stuart, Y.-H. Wan, J. Feng, R. E. Whaley, S. Singh, M. Boeckh, K. W. Cohen, M. J. McElrath, J. A. Englund, H. Y. Chu, M. Pancera, A. T. McGuire, L. Stamatatos, Analysis of a SARS-CoV-2-Infected Individual Reveals Development of Potent Neutralizing Antibodies with Limited Somatic Mutation. Immunity 53, 98-105.e5 (2020). doi:10.1016/j.immuni.2020.06.001 Medline

23. D. F. Robbiani, C. Gaebler, F. Muecksch, J. C. C. Lorenzi, Z. Wang, A. Cho, M. Agudelo, C. O. Barnes, A. Gazumyan, S. Finkin, T. Hägglöf, T. Y. Oliveira, C. Viant, A. Hurley, H.-H. Hoffmann, K. G. Millard, R. G. Kost, M. Cipolla, K. Gordon, F. Bianchini, S. T. Chen, V. Ramos, R. Patel, J. Dizon, I. Shimeliovich, P. Mendoza, H. Hartweger, L. Nogueira, M. Pack, J. Horowitz, F. Schmidt, Y. Weisblum, E. Michailidis, A. W. Ashbrook, E. Waltari, J. E. Pak, K. E. Huey-Tubman, N. Koranda, P. R. Hoffman, A. P. West Jr., C. M. Rice, T. Hatziioannou, P. J. Bjorkman, P. D. Bieniasz, M. Caskey, M. C. Nussenzweig, Convergent antibody responses to SARS-CoV-2 in convalescent individuals. Nature 584, 437-442 (2020). doi:10.1038/s41586-020-2456-9 Medline

24. P. J. M. Brouwer, T. G. Caniels, K. van der Straten, J. L. Snitselaar, Y. Aldon, S. Bangaru, J. L. Torres, N. M. A. Okba, M. Claireaux, G. Kerster, A. E. H. Bentlage, M. M. van Haaren, D. Guerra, J. A. Burger, E. E. Schermer, K. D. Verheul, N. van der Velde, A. van der Kooi, J. van Schooten, M. J. van Breemen, T. P. L. Bijl, K. Sliepen, A. Aartse, R. Derking, I. Bontjer, N. A. Kootstra, W. J. Wiersinga, G. Vidarsson, B. L. Haagmans, A. B. Ward, G. J. de Bree, R. W. Sanders, M. J. van Gils, Potent neutralizing antibodies from COVID-19 patients define multiple targets of vulnerability. Science 369, 643-650 (2020). doi:10.1126/science.abc5902 Medline

25. J. M. Dan, J. Mateus, Y. Kato, K. M. Hastie, E. D. Yu, C. E. Faliti, A. Grifoni, S. I. Ramirez, S. Haupt, A. Frazier, C. Nakao, V. Rayaprolu, S. A. Rawlings, B. Peters, F. Krammer, V. Simon, E. O. Saphire, D. M. Smith, D. Weiskopf, A. Sette, S. Crotty, Immunological memory to SARS-CoV-2 assessed for up to 8 months after infection. Science 371, eabf4063 (2021). doi:10.1126/science.abf4063 Medline

26. L. B. Rodda, J. Netland, L. Shehata, K. B. Pruner, P. A. Morawski, C. D. Thouvenel, K. K. Takehara, J. Eggenberger, E. A. Hemann, H. R. Waterman, M. L. Fahning, Y. Chen, M. Hale, J. Rathe, C. Stokes, S. Wrenn, B. Fiala, L. Carter, J. A. Hamerman, N. P. King, M. Gale Jr., D. J. Campbell, D. J. Rawlings, M. Pepper, Functional SARSCoV-2-Specific Immune Memory Persists after Mild COVID-19. Cell 184, 169183.e17 (2021). doi:10.1016/i.cell.2020.11.029 Medline

27. C. Gaebler, Z. Wang, J. C. C. Lorenzi, F. Muecksch, S. Finkin, M. Tokuyama, A. Cho, M. Jankovic, D. Schaefer-Babajew, T. Y. Oliveira, M. Cipolla, C. Viant, C. O. Barnes, Y. Bram, G. Breton, T. Hägglöf, P. Mendoza, A. Hurley, M. Turroja, K. Gordon, K. G.
Millard, V. Ramos, F. Schmidt, Y. Weisblum, D. Jha, M. Tankelevich, G. MartinezDelgado, J. Yee, R. Patel, J. Dizon, C. Unson-O'Brien, I. Shimeliovich, D. F. Robbiani, Z. Zhao, A. Gazumyan, R. E. Schwartz, T. Hatziioannou, P. J. Bjorkman, S. Mehandru, P. D. Bieniasz, M. Caskey, M. C. Nussenzweig, Evolution of antibody immunity to SARS-CoV-2. Nature 591, 639-644 (2021). doi:10.1038/s41586021-03207-w Medline

28. J. Seow, C. Graham, B. Merrick, S. Acors, S. Pickering, K. J. A. Steel, O. Hemmings, A. O'Byrne, N. Kouphou, R. P. Galao, G. Betancor, H. D. Wilson, A. W. Signell, H. Winstone, C. Kerridge, I. Huettner, J. M. Jimenez-Guardeño, M. J. Lista, N. Temperton, L. B. Snell, K. Bisnauthsing, A. Moore, A. Green, L. Martinez, B. Stokes, J. Honey, A. Izquierdo-Barras, G. Arbane, A. Patel, M. K. I. Tan, L. O'Connell, G. O'Hara, E. MacMahon, S. Douthwaite, G. Nebbia, R. Batra, R. Martinez-Nunez, M. Shankar-Hari, J. D. Edgeworth, S. J. D. Neil, M. H. Malim, K. J. Doores, Longitudinal observation and decline of neutralizing antibody responses in the three months following SARS-CoV-2 infection in humans. Nat. Microbiol. 5, 1598-1607 (2020). doi:10.1038/s41564-020-00813-8 Medline

29. F. Muecksch, H. Wise, B. Batchelor, M. Squires, E. Semple, C. Richardson, J. McGuire, S. Clearly, E. Furrie, N. Greig, G. Hay, K. Templeton, J. C. C. Lorenzi, T. Hatziioannou, S. Jenks, P. D. Bieniasz, Longitudinal Serological Analysis and Neutralizing Antibody Levels in Coronavirus Disease 2019 Convalescent Patients. J. Infect. Dis. 223, 389-398 (2021). doi:10.1093/infdis/jiaa659 Medline

30. L. Piccoli, Y.-J. Park, M. A. Tortorici, N. Czudnochowski, A. C. Walls, M. Beltramello, C. Silacci-Fregni, D. Pinto, L. E. Rosen, J. E. Bowen, O. J. Acton, S. Jaconi, B. Guarino, A. Minola, F. Zatta, N. Sprugasci, J. Bassi, A. Peter, A. De Marco, J. C. Nix, F. Mele, S. Jovic, B. F. Rodriguez, S. V. Gupta, F. Jin, G. Piumatti, G. Lo Presti, A. F. Pellanda, M. Biggiogero, M. Tarkowski, M. S. Pizzuto, E. Cameroni, C. HavenarDaughton, M. Smithey, D. Hong, V. Lepori, E. Albanese, A. Ceschi, E. Bernasconi, L. Elzi, P. Ferrari, C. Garzoni, A. Riva, G. Snell, F. Sallusto, K. Fink, H. W. Virgin, A. Lanzavecchia, D. Corti, D. Veesler, Mapping Neutralizing and Immunodominant Sites on the SARS-CoV-2 Spike Receptor-Binding Domain by Structure-Guided High-Resolution Serology. Cell 183, 1024-1042.e21 (2020). doi:10.1016/j.cell.2020.09.037 Medline

31. T. L. Steffen, E. T. Stone, M. Hassert, E. Geerling, B. T. Grimberg, A. M. Espino, P. Pantoja, C. Climent, D. F. Hoft, S. L. George, C. A. Sariol, A. K. Pinto, J. D. Brien, The receptor binding domain of SARS-CoV-2 spike is the key target of neutralizing antibody in human polyclonal sera. bioRxiv 2020.08.21.261727 [Preprint]. 22 August 2020. https://doi.org/10.1101/2020.08.21.261727.

32. C. O. Barnes, A. P. West Jr., K. E. Huey-Tubman, M. A. G. Hoffmann, N. G. Sharaf, P. R. Hoffman, N. Koranda, H. B. Gristick, C. Gaebler, F. Muecksch, J. C. Cetrulo Lorenzi, S. Finkin, T. Hägglöf, A. Hurley, K. G. Millard, Y. Weisblum, F. Schmidt, T. Hatziioannou, P. D. Bieniasz, M. Caskey, D. F. Robbiani, M. C. Nussenzweig, P. J. Bjorkman, Structures of Human Antibodies Bound to SARS-CoV-2 Spike Reveal Common Epitopes and Recurrent Features of Antibodies. Cell 182, 828-842.e16 (2020). doi:10.1016/i.cell.2020.06.025 Medline

33. L. Liu, P. Wang, M. S. Nair, J. Yu, M. Rapp, Q. Wang, Y. Luo, J. F.-W. Chan, V. Sahi, A. Figueroa, X. V. Guo, G. Cerutti, J. Bimela, J. Gorman, T. Zhou, Z. Chen, K.-Y. Yuen, P. D. Kwong, J. G. Sodroski, M. T. Yin, Z. Sheng, Y. Huang, L. Shapiro, D. D. Ho, Potent neutralizing antibodies against multiple epitopes on SARS-CoV-2 spike. Nature 584, 450-456 (2020). doi:10.1038/s41586-020-2571-7 Medline

34. J. Hansen, A. Baum, K. E. Pascal, V. Russo, S. Giordano, E. Wloga, B. O. Fulton, Y. Yan, K. Koon, K. Patel, K. M. Chung, A. Hermann, E. Ullman, J. Cruz, A. Rafique, T. Huang, J. Fairhurst, C. Libertiny, M. Malbec, W. Y. Lee, R. Welsh, G. Farr, S. Pennington, D. Deshpande, J. Cheng, A. Watty, P. Bouffard, R. Babb, N. Levenkova, C. Chen, B. Zhang, A. Romero Hernandez, K. Saotome, Y. Zhou, M. Franklin, S. Sivapalasingam, D. C. Lye, S. Weston, J. Logue, R. Haupt, M. Frieman, G. Chen, W. Olson, A. J. Murphy, N. Stahl, G. D. Yancopoulos, C. A. Kyratsous, Studies in humanized mice and convalescent humans yield a SARS-CoV-2 antibody cocktail. Science 369, 1010-1014 (2020). doi:10.1126/science.abd0827 Medline

35. B. Ju, Q. Zhang, J. Ge, R. Wang, J. Sun, X. Ge, J. Yu, S. Shan, B. Zhou, S. Song, X. Tang, J. Yu, J. Lan, J. Yuan, H. Wang, J. Zhao, S. Zhang, Y. Wang, X. Shi, L. Liu, J. Zhao, X. Wang, Z. Zhang, L. Zhang, Human neutralizing antibodies elicited by SARS-CoV-2 infection. Nature 584, 115-119 (2020). doi:10.1038/s41586-0202380-z Medline

36. Y. Cao, B. Su, X. Guo, W. Sun, Y. Deng, L. Bao, Q. Zhu, X. Zhang, Y. Zheng, C. Geng, 
X. Chai, R. He, X. Li, Q. Lv, H. Zhu, W. Deng, Y. Xu, Y. Wang, L. Qiao, Y. Tan, L. Song, G. Wang, X. Du, N. Gao, J. Liu, J. Xiao, X. D. Su, Z. Du, Y. Feng, C. Qin, C. Qin, R. Jin, X. S. Xie, Potent Neutralizing Antibodies against SARS-CoV-2 Identified by HighThroughput Single-Cell Sequencing of Convalescent Patients' B Cells. Cell 182, 73-84.e16 (2020). doi:10.1016/i.cell.2020.05.025 Medline

37. A. J. Greaney, T. N. Starr, P. Gilchuk, S. J. Zost, E. Binshtein, A. N. Loes, S. K. Hilton, J. Huddleston, R. Eguia, K. H. D. Crawford, A. S. Dingens, R. S. Nargi, R. E. Sutton, N. Suryadevara, P. W. Rothlauf, Z. Liu, S. P. J. Whelan, R. H. Carnahan, J. E. Crowe Jr., J. D. Bloom, Complete Mapping of Mutations to the SARS-CoV-2 Spike Receptor-Binding Domain that Escape Antibody Recognition. Cell Host Microbe 29, 44-57.e9 (2021). doi:10.1016/i.chom.2020.11.007 Medline

38. X. Chi, R. Yan, J. Zhang, G. Zhang, Y. Zhang, M. Hao, Z. Zhang, P. Fan, Y. Dong, Y. Yang, Z. Chen, Y. Guo, J. Zhang, Y. Li, X. Song, Y. Chen, L. Xia, L. Fu, L. Hou, J. Xu, C. Yu, J. Li, Q. Zhou, W. Chen, A neutralizing human antibody binds to the Nterminal domain of the Spike protein of SARS-CoV-2. Science 369, 650-655 (2020). doi:10.1126/science.abc6952 Medline

39. M. McCallum, A. De Marco, F. Lempp, M. A. Tortorici, D. Pinto, A. C. Walls, M. Beltramello, A. Chen, Z. Liu, F. Zatta, S. Zepeda, J. di lulio, J. E. Bowen, M. MontielRuiz, J. Zhou, L. E. Rosen, S. Bianchi, B. Guarino, C. S. Fregni, R. Abdelnabi, S.-Y. C. Foo, P. W. Rothlauf, L.-M. Bloyet, F. Benigni, E. Cameroni, J. Neyts, A. Riva, G. Snell, A. Telenti, S. P. J. Whelan, H. W. Virgin, D. Corti, M. S. Pizzuto, D. Veesler, Nterminal domain antigenic mapping reveals a site of vulnerability for SARS-CoV2. bioRxiv 2021.01.14.426475 [Preprint]. 14 January 2021. https://doi.org/10.1101/2021.01.14.426475.

40. G. Cerutti, Y. Guo, T. Zhou, J. Gorman, M. Lee, M. Rapp, E. R. Reddem, J. Yu, F. Bahna, J. Bimela, Y. Huang, P. S. Katsamba, L. Liu, M. S. Nair, R. Rawi, A. S. Olia, P. Wang, B. Zhang, G.-Y. Chuang, D. D. Ho, Z. Sheng, P. D. Kwong, L. Shapiro, Potent SARS-CoV-2 Neutralizing Antibodies Directed Against Spike N-Terminal Domain Target a Single Supersite. Cell Host Microbe 10.1016/j.chom.2021.03.005 (2021). doi:10.1016/i.chom.2021.03.005 Medline

41. G. Song, W.-t. He, S. Callaghan, F. Anzanello, D. Huang, J. Ricketts, J. L. Torres, N. Beutler, L. Peng, S. Vargas, J. Cassell, M. Parren, L. Yang, C. Ignacio, D. M. Smith, J. E. Voss, D. Nemazee, A. B. Ward, T. Rogers, D. R. Burton, R. Andrabi, Crossreactive serum and memory $B$ cell responses to spike protein in SARS-CoV-2 and endemic coronavirus infection. bioRxiv 2020.09.22.308965 [Preprint]. 23 September 2020. https://doi.org/10.1101/2020.09.22.308965.

42. C. Wang, R. van Haperen, J. Gutiérrez-Álvarez, W. Li, N. M. A. Okba, I. Albulescu, I. Widjaja, B. van Dieren, R. Fernandez-Delgado, I. Sola, D. L. Hurdiss, O. Daramola, F. Grosveld, F. J. M. van Kuppeveld, B. L. Haagmans, L. Enjuanes, D. Drabek, B.-J. Bosch, Isolation of cross-reactive monoclonal antibodies against divergent human coronaviruses that delineate a conserved and vulnerable site on the spike protein. bioRxiv 2020.10.20.346916 [Preprint]. 20 October 2020. https://doi.org/10.1101/2020.10.20.346916.

43. F. Wu, S. Zhao, B. Yu, Y.-M. Chen, W. Wang, Z.-G. Song, Y. Hu, Z.-W. Tao, J.-H. Tian, Y.-Y. Pei, M.-L. Yuan, Y.-L. Zhang, F.-H. Dai, Y. Liu, Q.-M. Wang, J.-J. Zheng, L. Xu, E. C. Holmes, Y.-Z. Zhang, A new coronavirus associated with human respiratory disease in China. Nature 579, 265-269 (2020). doi:10.1038/s41586-020-2008-3 Medline

44. L. R. Baden, H. M. El Sahly, B. Essink, K. Kotloff, S. Frey, R. Novak, D. Diemert, S. A. Spector, N. Rouphael, C. B. Creech, J. McGettigan, S. Khetan, N. Segall, J. Solis, A. Brosz, C. Fierro, H. Schwartz, K. Neuzil, L. Corey, P. Gilbert, H. Janes, D. Follmann, M. Marovich, J. Mascola, L. Polakowski, J. Ledgerwood, B. S. Graham, H. Bennett, R. Pajon, C. Knightly, B. Leav, W. Deng, H. Zhou, S. Han, M. Ivarsson, J. Miller, T. Zaks, COVE Study Group, Efficacy and Safety of the mRNA-1273 SARSCoV-2 Vaccine. N. Engl. J. Med. 384, 403-416 (2021). doi:10.1056/NEJMoa2035389 Medline

45. K. S. Corbett, D. K. Edwards, S. R. Leist, O. M. Abiona, S. Boyoglu-Barnum, R. A. Gillespie, S. Himansu, A. Schäfer, C. T. Ziwawo, A. T. DiPiazza, K. H. Dinnon, S. M. Elbashir, C. A. Shaw, A. Woods, E. J. Fritch, D. R. Martinez, K. W. Bock, M. Minai, B. M. Nagata, G. B. Hutchinson, K. Wu, C. Henry, K. Bahl, D. Garcia-Dominguez, L. Ma, I. Renzi, W.-P. Kong, S. D. Schmidt, L. Wang, Y. Zhang, E. Phung, L. A. Chang, R. J. Loomis, N. E. Altaras, E. Narayanan, M. Metkar, V. Presnyak, C. Liu, M. K. Louder, W. Shi, K. Leung, E. S. Yang, A. West, K. L. Gully, L. J. Stevens, N. Wang, D. Wrapp, N. A. Doria-Rose, G. Stewart-Jones, H. Bennett, G. S. Alvarado, M. C. Nason, T. J. Ruckwardt, J. S. McLellan, M. R. Denison, J. D. Chappell, I. N. Moore,
K. M. Morabito, J. R. Mascola, R. S. Baric, A. Carfi, B. S. Graham, SARS-CoV-2 mRNA vaccine design enabled by prototype pathogen preparedness. Nature 586 , 567-571 (2020). doi:10.1038/s41586-020-2622-0 Medline

46. F. P. Polack, S. J. Thomas, N. Kitchin, J. Absalon, A. Gurtman, S. Lockhart, J. L. Perez, G. Pérez Marc, E. D. Moreira, C. Zerbini, R. Bailey, K. A. Swanson, S. Roychoudhury, K. Koury, P. Li, W. V. Kalina, D. Cooper, R. W. Frenck Jr., L. L. Hammitt, Ö. Türeci, H. Nell, A. Schaefer, S. Ünal, D. B. Tresnan, S. Mather, P. R. Dormitzer, U. Şahin, K. U. Jansen, W. C. Gruber, C4591001 Clinical Trial Group, Safety and Efficacy of the BNT162b2 mRNA Covid-19 Vaccine. N. Engl. J. Med. 383, 2603-2615 (2020). doi:10.1056/NEJMoa2034577 Medline

47. A. B. Vogel, I. Kanevsky, Y. Che, K. A. Swanson, A. Muik, M. Vormehr, L. M. Kranz, K. C. Walzer, S. Hein, A. Güler, J. Loschko, M. S. Maddur, K. Tompkins, J. Cole, B. G. Lui, T. Ziegenhals, A. Plaschke, D. Eisel, S. C. Dany, S. Fesser, S. Erbar, F. Bates, D. Schneider, B. Jesionek, B. Sänger, A. K. Wallisch, Y. Feuchter, H. Junginger, S. A. Krumm, A. P. Heinen, P. Adams-Quack, J. Schlereth, C. Kröner, S. Hall-Ursone, K. Brasky, M. C. Griffor, S. Han, J. A. Lees, E. H. Mashalidis, P. V. Sahasrabudhe, C. Y. Tan, D. Pavliakova, G. Singh, C. Fontes-Garfias, M. Pride, I. L. Scully, T. Ciolino, J. Obregon, M. Gazi, R. Carrion Jr., K. J. Alfson, W. V. Kalina, D. Kaushal, P.-Y. Shi, T. Klamp, C. Rosenbaum, A. N. Kuhn, Ö. Türeci, P. R. Dormitzer, K. U. Jansen, U. Sahin, A prefusion SARS-CoV-2 spike RNA vaccine is highly immunogenic and prevents lung infection in non-human primates. bioRxiv 2020.09.08.280818 [Preprint]. 8 September 2020. https://doi.org/10.1101/2020.09.08.280818.

48. L. A. Jackson, E. J. Anderson, N. G. Rouphael, P. C. Roberts, M. Makhene, R. N. Coler, M. P. McCullough, J. D. Chappell, M. R. Denison, L. J. Stevens, A. J. Pruijssers, A. McDermott, B. Flach, N. A. Doria-Rose, K. S. Corbett, K. M. Morabito, S. O'Dell, S. D. Schmidt, P. A. Swanson 2nd, M. Padilla, J. R. Mascola, K. M. Neuzil, H. Bennett, W. Sun, E. Peters, M. Makowski, J. Albert, K. Cross, W. Buchanan, R. Pikaart-Tautges, J. E. Ledgerwood, B. S. Graham, J. H. Beigel, mRNA-1273 Study Group, An mRNA Vaccine against SARS-CoV-2-Preliminary Report. N. Engl. J. Med. 383, 1920-1931 (2020). doi:10.1056/NEJMoa2022483 Medline

49. E. E. Walsh, R. W. Frenck Jr., A. R. Falsey, N. Kitchin, J. Absalon, A. Gurtman, S. Lockhart, K. Neuzil, M. J. Mulligan, R. Bailey, K. A. Swanson, P. Li, K. Koury, W. Kalina, D. Cooper, C. Fontes-Garfias, P.-Y. Shi, Ö. Türeci, K. R. Tompkins, K. E. Lyke, V. Raabe, P. R. Dormitzer, K. U. Jansen, U. Şahin, W. C. Gruber, Safety and Immunogenicity of Two RNA-Based Covid-19 Vaccine Candidates. N. Engl. J. Med. 383, 2439-2450 (2020). doi:10.1056/NEJMoa2027906 Medline

50. A. Rambaut, N. Loman, O. Pybus, W. Barclay, J. Barrett, A. Carabelli, T. Connor, T. Peacock, D. L. Robertson, E. Volz, COVID-19 Genomics Consortium UK (CoG-UK), "Preliminary genomic characterisation of an emergent SARS-CoV-2 lineage in the UK defined by a novel set of spike mutations" (Virological, 2021); https://virological.org/t/preliminary-genomic-characterisation-of-anemergent-sars-cov-2-lineage-in-the-uk-defined-by-a-novel-set-of-spikemutations $/ 563$.

51. E. Volz, S. Mishra, M. Chand, J. C. Barrett, R. Johnson, L. Geidelberg, W. R. Hinsley, D. J. Laydon, G. Dabrera, Á. O'Toole, R. Amato, M. Ragonnet-Cronin, I. Harrison, B. Jackson, C. V. Ariani, O. Boyd, N. J. Loman, J. T. McCrone, S. Gonçalves, D. Jorgensen, R. Myers, V. Hill, D. K. Jackson, K. Gaythorpe, N. Groves, J. Sillitoe, D. P. Kwiatkowski, The COVID-19 Genomics UK (COG-UK) consortium, S. Flaxman, O. Ratmann, S. Bhatt, S. Hopkins, A. Gandy, A. Rambaut, N. M. Ferguson, Transmission of SARS-CoV-2 Lineage B.1.1.7 in England: Insights from linking epidemiological and genetic data. medRxiv 2020.12.30.20249034 [Preprint]. 4 January 2021. https://doi.org/10.1101/2020.12.30.20249034.

52. H. Tegally, E. Wilkinson, M. Giovanetti, A. Iranzadeh, V. Fonseca, J. Giandhari, D. Doolabh, S. Pillay, E. J. San, N. Msomi, K. Mlisana, A. von Gottberg, S. Walaza, M. Allam, A. Ismail, T. Mohale, A. J. Glass, S. Engelbrecht, G. Van Zyl, W. Preiser, F. Petruccione, A. Sigal, D. Hardie, G. Marais, M. Hsiao, S. Korsman, M.-A. Davies, L. Tyers, I. Mudau, D. York, C. Maslo, D. Goedhals, S. Abrahams, O. Laguda-Akingba, A. Alisoltani-Dehkordi, A. Godzik, C. K. Wibmer, B. T. Sewell, J. Lourenço, L. C. J. Alcantara, S. L. Kosakovsky Pond, S. Weaver, D. Martin, R. J. Lessells, J. N. Bhiman, C. Williamson, T. de Oliveira, Emergence and rapid spread of a new severe acute respiratory syndrome-related coronavirus 2 (SARS-CoV-2) lineage with multiple spike mutations in South Africa. medRxiv 2020.12.21.20248640 [Preprint]. 22 December 2020. https://doi.org/10.1101/2020.12.21.20248640.

53. N. G. Davies, S. Abbott, R. C. Barnard, C. I. Jarvis, A. J. Kucharski, J. D. Munday, C. A. B. Pearson, T. W. Russell, D. C. Tully, A. D. Washburne, T. Wenseleers, A. 
Gimma, W. Waites, K. L. M. Wong, K. van Zandvoort, J. D. Silverman, CMMID COVID-19 Working Group, The COVID-19 Genomics UK (COG-UK) Consortium, K. Diaz-Ordaz, R. Keogh, R. M. Eggo, S. Funk, M. Jit, K. E. Atkins, W. J. Edmunds, Estimated transmissibility and impact of SARS-CoV-2 lineage B.1.1.7 in England. medRxiv 2020.12.24.20248822 [Preprint]. 5 March 2021. https://doi.org/10.1101/2020.12.24.20248822.

54. E. C. Sabino, L. F. Buss, M. P. S. Carvalho, C. A. Prete Jr., M. A. E. Crispim, N. A. Fraiji, R. H. M. Pereira, K. V. Parag, P. da Silva Peixoto, M. U. G. Kraemer, M. K. Oikawa, T. Salomon, Z. M. Cucunuba, M. C. Castro, A. A. de Souza Santos, V. H. Nascimento, H. S. Pereira, N. M. Ferguson, O. G. Pybus, A. Kucharski, M. P. Busch, C. Dye, N. R. Faria, Resurgence of COVID-19 in Manaus, Brazil, despite high seroprevalence. Lancet 397, 452-455 (2021). doi:10.1016/S01406736(21)00183-5 Medline

55. N. R. Faria, I. Morales Claro, D. Candido, L. A. Moyses Franco, P. S. Andrade, T. M. Coletti, C. A. M. Silva, F. C. Sales, E. R. Manuli, R. S. Aguiar, N. Gaburo, C. d. C. Camilo, N. A. Fraiji, M. A. Esashika Crispim, M. d. P. S. S. Carvalho, A. Rambaut, N. Loman, 0. G. Pybus, E. C. Sabino, CADDE Genomic Network, "Genomic characterisation of an emergent SARS-CoV-2 lineage in Manaus: preliminary findings" (Virological, 2021); https://virological.org/t/genomiccharacterisation-of-an-emergent-sars-cov-2-lineage-in-manaus-preliminaryfindings/586.

56. Á. O'Toole, V. Hill, O. G. Pybus, A. Watts, I. I. Bogoch, K. Khan, J. P. Messina, The COVID-19 Genomics UK (COG-UK) consortium, Network for Genomic Surveillance in South Africa (NGS-SA), Brazil-UK CADDE Genomic Network, H. Tegally, R. R. Lessells, J. Giandhari, S. Pillay, K. A. Tumedi, G. Nyepetsi, M. Kebabonye, M. Matsheka, M. Mine, S. Tokajian, H. Hassan, T. Salloum, G. Merhi, J. Koweyes, J. L. Geoghegan, J. de Ligt, X. Ren, M. Storey, N. E. Freed, C. Pattabiraman, P. Prasad, A. S. Desai, R. Vasanthapuram, T. F. Schulz, L. Steinbrück, T. Stadler, Swiss Viollier Sequencing Consortium, A. Parisi, A. Bianco, D. G. de Viedma, S. BuenestadoSerrano, V. Borges, J. Isidro, S. Duarte, J. P. Gomes, N. S. Zuckerman, M. Mandelboim, O. Mor, T. Seemann, A. Arnott, J. Draper, M. Gall, W. Rawlinson, I. Deveson, S. Schlebusch, J. McMahon, L. Leong, C. K. Lim, M. Chironna, D. Laconsole, A. Bal, L. Josset, E. Holmes, K. St George, E. Lasek-Nesselquist, R. S. Sikkema, B. B. Oude Munnink, M. Koopmans, M. Brytting, V. S. Rani, S. Pavani, T. Smura, A. Heim, S. Kurkela, M. Umair, M. Salman, B. Bartolini, M. Rueca, C. Drosten, T. Wolff, O. Silander, D. Eggink, C. Reusken, H. Vennema, A. Park, SEARCH Alliance San Diego, National Virus Reference Laboratory, SeqCOVIDSpain, Danish Covid-19 Genome Consortium (DCGC), Communicable Diseases Genomic Network (CDGN), Dutch National SARS-CoV-2 surveillance program, Division of Emerging Infectious Diseases KDCA, T. de Oliveira, N. R. Faria, A. Rambaut, M. U. G. Kraemer, "Tracking the international spread of SARS-CoV-2 lineages B.1.1.7 and B.1.351/501Y-V2" (Virological, 2021); https://virological.org/t/tracking-the-international-spread-of-sars-cov-2ineages-b-1-1-7-and-b-1-351-501y- $v 2 / 592$.

57. K. K. Chan, T. J. C. Tan, K. K. Narayanan, E. Procko, An engineered decoy receptor for SARS-CoV-2 broadly binds protein $S$ sequence variants. bioRxiv $\begin{array}{llll}\text { 2020.10.18.344622 } & \text { [Preprint]. } 21 & \text { December } & 2020 .\end{array}$ https://doi.org/10.1101/2020.10.18.344622.

58. T. N. Starr, A. J. Greaney, A. Addetia, W. W. Hannon, M. C. Choudhary, A. S. Dingens, J. Z. Li, J. D. Bloom, Prospective mapping of viral mutations that escape antibodies used to treat COVID-19. Science 371, 850-854 (2021). doi:10.1126/science.abf9302 Medline

59. L. Zhang, C. B. Jackson, H. Mou, A. Ojha, H. Peng, B. D. Quinlan, E. S. Rangarajan, A. Pan, A. Vanderheiden, M. S. Suthar, W. Li, T. Izard, C. Rader, M. Farzan, H. Choe, SARS-CoV-2 spike-protein D614G mutation increases virion spike density and infectivity. Nat. Commun. 11, 6013 (2020). doi:10.1038/s41467-020-19808-4 Medline

60. B. Zhou, T. Thi Nhu Thao, D. Hoffmann, A. Taddeo, N. Ebert, F. Labroussaa, A. Pohlmann, J. King, S. Steiner, J. N. Kelly, J. Portmann, N. J. Halwe, L. Ulrich, B. S. Trüeb, X. Fan, B. Hoffmann, L. Wang, L. Thomann, X. Lin, H. Stalder, B. Pozzi, S. de Brot, N. Jiang, D. Cui, J. Hossain, M. Wilson, M. Keller, T. J. Stark, J. R. Barnes, R. Dijkman, J. Jores, C. Benarafa, D. E. Wentworth, V. Thiel, M. Beer, SARS-CoV-2 spike D614G change enhances replication and transmission. Nature 10.1038/s41586-021-03361-1 (2021). doi:10.1038/s41586-021-03361-1 Medline

61. Z. Liu, L. A. VanBlargan, L.-M. Bloyet, P. W. Rothlauf, R. E. Chen, S. Stumpf, H. Zhao,
J. M. Errico, E. S. Theel, M. J. Liebeskind, B. Alford, W. J. Buchser, A. H. Ellebedy, D. H. Fremont, M. S. Diamond, S. P. J. Whelan, Landscape analysis of escape variants identifies SARS-CoV-2 spike mutations that attenuate monoclonal and serum antibody neutralization. bioRxiv 2020.11.06.372037 [Preprint]. 11 January 2021. https://doi.org/10.1101/2020.11.06.372037.

62. A. Baum, B. O. Fulton, E. Wloga, R. Copin, K. E. Pascal, V. Russo, S. Giordano, K. Lanza, N. Negron, M. Ni, Y. Wei, G. S. Atwal, A. J. Murphy, N. Stahl, G. D. Yancopoulos, C. A. Kyratsous, Antibody cocktail to SARS-CoV-2 spike protein prevents rapid mutational escape seen with individual antibodies. Science 369 , 1014-1018 (2020). doi:10.1126/science.abd0831 Medline

63. Q. Li, J. Wu, J. Nie, L. Zhang, H. Hao, S. Liu, C. Zhao, Q. Zhang, H. Liu, L. Nie, H. Qin, M. Wang, Q. Lu, X. Li, Q. Sun, J. Liu, L. Zhang, X. Li, W. Huang, Y. Wang, The Impact of Mutations in SARS-CoV-2 Spike on Viral Infectivity and Antigenicity. Cell 182. 1284-1294.e9 (2020). doi:10.1016/j.cell.2020.07.012 Medline

64. Y. Weisblum, F. Schmidt, F. Zhang, J. DaSilva, D. Poston, J. C. C. Lorenzi, F. Muecksch, M. Rutkowska, H.-H. Hoffmann, E. Michailidis, C. Gaebler, M. Agudelo, A. Cho, Z. Wang, A. Gazumyan, M. Cipolla, L. Luchsinger, C. D. Hillyer, M. Caskey, D. F. Robbiani, C. M. Rice, M. C. Nussenzweig, T. Hatziioannou, P. D. Bieniasz, Escape from neutralizing antibodies by SARS-CoV-2 spike protein variants. eLife 9, e61312 (2020). doi:10.7554/eLife.61312 Medline

65. E. C. Thomson, L. E. Rosen, J. G. Shepherd, R. Spreafico, A. da Silva Filipe, J. A. Wojcechowskyj, C. Davis, L. Piccoli, D. J. Pascall, J. Dillen, S. Lytras, N. Czudnochowski, R. Shah, M. Meury, N. Jesudason, A. De Marco, K. Li, J. Bassi, A. O'Toole, D. Pinto, R. M. Colquhoun, K. Culap, B. Jackson, F. Zatta, A. Rambaut, S. Jaconi, V. B. Sreenu, J. Nix, I. Zhang, R. F. Jarrett, W. G. Glass, M. Beltramello, K. Nomikou, M. Pizzuto, L. Tong, E. Cameroni, T. I. Croll, N. Johnson, J. Di lulio, A. Wickenhagen, A. Ceschi, A. M. Harbison, D. Mair, P. Ferrari, K. Smollett, F. Sallusto, S. Carmichael, C. Garzoni, J. Nichols, M. Galli, J. Hughes, A. Riva, A. Ho, M. Schiuma, M. G. Semple, P. J. M. Openshaw, E. Fadda, J. K. Baillie, J. D. Chodera, The ISARIC4C Investigators, COVID-19 Genomics UK (COG-UK) Consortium, S. J. Rihn, S. J. Lycett, H. W. Virgin, A. Telenti, D. Corti, D. L. Robertson, G. Snell, Circulating SARS-CoV-2 spike N439K variants maintain fitness while evading antibody-mediated immunity. Cell 184, 1171-1187.e20 (2021). doi:10.1016/i.cell.2021.01.037 Medline

66. P. Wang, M. S. Nair, L. Liu, S. Iketani, Y. Luo, Y. Guo, M. Wang, J. Yu, B. Zhang, P. D. Kwong, B. S. Graham, J. R. Mascola, J. Y. Chang, M. T. Yin, M. Sobieszczyk, C. A. Kyratsous, L. Shapiro, Z. Sheng, Y. Huang, D. D. Ho, Antibody Resistance of SARS-CoV-2 Variants B.1.351 and B.1.1.7. bioRxiv 2021.01.25.428137 [Preprint]. 12 February 2021. https://doi.org/10.1101/2021.01.25.428137.

67. C. Graham, J. Seow, I. Huettner, H. Khan, N. Kouphou, S. Acors, H. Winstone, S. Pickering, R. P. Galao, M. J. Lista, J. M. Jimenez-Guardeno, A. G. Laing, Y. Wu, M. Joseph, L. Muir, W. M. Ng, H. M. E. Duyvesteyn, Y. Zhao, T. A. Bowden, M. ShankarHari, A. Rosa, P. Cherepanov, L. E. McCoy, A. C. Hayday, S. J. D. Neil, M. H. Malim, K. J. Doores, Impact of the B.1.1.7 variant on neutralizing monoclonal antibodies recognizing diverse epitopes on SARS-CoV-2 Spike. bioRxiv 2021.02.03.429355 [Preprint]. 3 February 2021. https://doi.org/10.1101/2021.02.03.429355.

68. X. Shen, H. Tang, C. McDanal, K. Wagh, W. Fischer, J. Theiler, H. Yoon, D. Li, B. F. Haynes, K. O. Sanders, S. Gnanakaran, N. Hengartner, R. Pajon, G. Smith, G. M. Glenn, B. Korber, D. C. Montefiori, SARS-CoV-2 variant B.1.1.7 is susceptible to neutralizing antibodies elicited by ancestral spike vaccines. Cell Host Microbe 10.1016/i.chom.2021.03.002 (2021). doi:10.1016/i.chom.2021.03.002

69. C. K. Wibmer, F. Ayres, T. Hermanus, M. Madzivhandila, P. Kgagudi, B. Oosthuysen, B. E. Lambson, T. de Oliveira, M. Vermeulen, K. van der Berg, T. Rossouw, M. Boswell, V. Ueckermann, S. Meiring, A. von Gottberg, C. Cohen, L. Morris, J. N. Bhiman, P. L. Moore, SARS-CoV-2 501Y.V2 escapes neutralization by South African COVID-19 donor plasma. Nat. Med. 10.1038/s41591-021-01285-x (2021). doi:10.1038/s41591-021-01285-x Medline

70. Z. Wang, F. Schmidt, Y. Weisblum, F. Muecksch, C. O. Barnes, S. Finkin, D. Schaefer-Babajew, M. Cipolla, C. Gaebler, J. A. Lieberman, T. Y. Oliveira, Z. Yang, M. E. Abernathy, K. E. Huey-Tubman, A. Hurley, M. Turroja, K. A. West, K. Gordon, K. G. Millard, V. Ramos, J. Da Silva, J. Xu, R. A. Colbert, R. Patel, J. Dizon, C. UnsonO'Brien, I. Shimeliovich, A. Gazumyan, M. Caskey, P. J. Bjorkman, R. Casellas, T. Hatziioannou, P. D. Bieniasz, M. C. Nussenzweig, mRNA vaccine-elicited antibodies to SARS-CoV-2 and circulating variants. Nature 10.1038/s41586-02103324-6 (2021). doi:10.1038/s41586-021-03324-6 Medline 
71. Johnson \& Johnson, “Johnson \& Johnson Announces Single-Shot Janssen COVID19 Vaccine Candidate Met Primary Endpoints in Interim Analysis of its Phase 3 ENSEMBLE Trial" (2021); www.prnewswire.com/news-releases/iohnson-johnson-announces-single-shot-janssen-covid-19-vaccine-candidate-metprimary-endpoints-in-interim-analysis-of-its-phase-3-ensemble-trial$301218035 \mathrm{htm}$

72. Novavax, Inc., "Novavax COVID-19 Vaccine Demonstrates 89.3\% Efficacy in UK Phase 3 Trial" (2021); https://ir.novavax.com/news-releases/news-releasedetails/novavax-covid-19-vaccine-demonstrates-893-efficacy-uk-phase-3.

73. M. Yuan, H. Liu, N. C. Wu, C. D. Lee, X. Zhu, F. Zhao, D. Huang, W. Yu, Y. Hua, H Tien, T. F. Rogers, E. Landais, D. Sok, J. G. Jardine, D. R. Burton, I. A. Wilson, Structural basis of a shared antibody response to SARS-CoV-2. Science 369, 1119-1123 (2020). doi:1.0.1126/science.abd2321 Medline

74. N. C. Wu, M. Yuan, H. Liu, C. D. Lee, X. Zhu, S. Bangaru, J. L. Torres, T. G. Caniels, P. J. M. Brouwer, M. J. van Gils, R. W. Sanders, A. B. Ward, I. A. Wilson, An Alternative Binding Mode of IGHV3-53 Antibodies to the SARS-CoV-2 Receptor Binding Domain. Cell Rep. 33, 108274 (2020). doi:10.1016/j.celrep.2020.108274 Medline

75. Y. Wu, F. Wang, C. Shen, W. Peng, D. Li, C. Zhao, Z. Li, S. Li, Y. Bi, Y. Yang, Y. Gong, H. Xiao, Z. Fan, S. Tan, G. Wu, W. Tan, X. Lu, C. Fan, Q. Wang, Y. Liu, C. Zhang, J. Qi, G. F. Gao, F. Gao, L. Liu, A noncompeting pair of human neutralizing antibodies block COVID-19 virus binding to its receptor ACE2. Science 368, 1274-1278 (2020). doi:10.1126/science. abc2241 Medline

76. R. Shi, C. Shan, X. Duan, Z. Chen, P. Liu, J. Song, T. Song, X. Bi, C. Han, L. Wu, G. Gao, X. Hu, Y. Zhang, Z. Tong, W. Huang, W. J. Liu, G. Wu, B. Zhang, L. Wang, J. Qi, H. Feng, F.-S. Wang, Q. Wang, G. F. Gao, Z. Yuan, J. Yan, A human neutralizing antibody targets the receptor-binding site of SARS-CoV-2. Nature 584, 120-124 (2020). doi:10.1038/s41586-020-2381-y Medline

77. S. Du, Y. Cao, Q. Zhu, P. Yu, F. Qi, G. Wang, X. Du, L. Bao, W. Deng, H. Zhu, J. Liu, J. Nie, Y. Zheng, H. Liang, R. Liu, S. Gong, H. Xu, A. Yisimayi, Q. Lv, B. Wang, R. He, Y. Han, W. Zhao, Y. Bai, Y. Qu, X. Gao, C. Ji, Q. Wang, N. Gao, W. Huang, Y. Wang, X. S. Xie, X. D. Su, J. Xiao, C. Qin, Structurally Resolved SARS-CoV-2 Antibody Shows High Efficacy in Severely Infected Hamsters and Provides a Potent Cocktail Pairing Strategy. Cell 183, 1013-1023.e13 (2020). doi:10.1016/i.cell.2020.09.035 Medline

78. N. K. Hurlburt, E. Seydoux, Y.-H. Wan, V. V. Edara, A. B. Stuart, J. Feng, M. S Suthar, A. T. McGuire, L. Stamatatos, M. Pancera, Structural basis for potent neutralization of SARS-CoV-2 and role of antibody affinity maturation. Nat. Commun. 11, 5413 (2020). doi:10.1038/s41467-020-19231-9 Medline

79. J. Snijder, M. S. Ortego, C. Weidle, A. B. Stuart, M. D. Gray, M. J. McElrath, M. Pancera, D. Veesler, A. T. McGuire, An Antibody Targeting the Fusion Machinery Neutralizes Dual-Tropic Infection and Defines a Site of Vulnerability on EpsteinBarr Virus. Immunity 48, 799-811.e9 (2018). doi:10.1016/i.immuni.2018.03.026 Medline

80. S. Saadat, Z. R. Tehrani, J. Logue, M. Newman, M. B. Frieman, A. D. Harris, M. M. Sajadi, Binding and Neutralization Antibody Titers After a Single Vaccine Dose in Health Care Workers Previously Infected With SARS-CoV-2. JAMA 10.1001/jama.2021.3341 (2021). doi:10.1001/jama.2021.3341 Medline

81. F. Krammer, K. Srivastava, H. Alshammary, A. A. Amoako, M. H. Awawda, K. F. Beach, M. C. Bermúdez-González, D. A. Bielak, J. M. Carreño, R. L. Chernet, L. Q. Eaker, E. D. Ferreri, D. L. Floda, C. R. Gleason, J. Z. Hamburger, K. Jiang, G. Kleiner, D. Jurczyszak, J. C. Matthews, W. A. Mendez, I. Nabeel, L. C. F. Mulder, A. J. Raskin, K. T. Russo, A. T. Salimbangon, M. Saksena, A. S. Shin, G. Singh, L. A. Sominsky, D. Stadlbauer, A. Wajnberg, V. Simon, Antibody Responses in Seropositive Persons after a Single Dose of SARS-CoV-2 mRNA Vaccine. N. Engl. J. Med. 10.1056/NEJMc2101667 (2021). doi:10.1056/NEJMc2101667 Medline

82. Y. Wan, J. Shang, R. Graham, R. S. Baric, F. Li, Receptor Recognition by the Novel Coronavirus from Wuhan: An Analysis Based on Decade-Long Structural Studies of SARS Coronavirus. J. Virol. 94, e00127-20 (2020). doi:10.1128/JVl.00127-20 Medline

83. Y. Liu, J. Liu, H. Xia, X. Zhang, C. R. Fontes-Garfias, K. A. Swanson, H. Cai, R. Sarkar, W. Chen, M. Cutler, D. Cooper, S. C. Weaver, A. Muik, U. Sahin, K. U. Jansen, X. Xie, P. R. Dormitzer, P.-Y. Shi, Neutralizing Activity of BNT162b2-Elicited Serum. N. Engl. J. Med. 10.1056/NEJMc2102017 (2021). doi:10.1056/NEJMc2102017 Medline
84. K. Wu, A. P. Werner, M. Koch, A. Choi, E. Narayanan, G. B. E. Stewart-Jones, T. Colpitts, H. Bennett, S. Boyoglu-Barnum, W. Shi, J. I. Moliva, N. J. Sullivan, B. S. Graham, A. Carfi, K. S. Corbett, R. A. Seder, D. K. Edwards, Serum Neutralizing Activity Elicited by mRNA-1273 Vaccine. N. Engl. J. Med. 10.1056/NEJMc2102179 (2021). doi:10.1056/NEJMc2102179 Medline

85. K. E. Kistler, T. Bedford, Evidence for adaptive evolution in the receptor-binding domain of seasonal coronaviruses OC43 and 229e. eLife 10, e64509 (2021). doi:10.7554/eLife.64509 Medline

86. D. Pinto, Y.-J. Park, M. Beltramello, A. C. Walls, M. A. Tortorici, S. Bianchi, S. Jaconi, K. Culap, F. Zatta, A. De Marco, A. Peter, B. Guarino, R. Spreafico, E. Cameroni, J. B. Case, R. E. Chen, C. Havenar-Daughton, G. Snell, A. Telenti, H. W. Virgin, A. Lanzavecchia, M. S. Diamond, K. Fink, D. Veesler, D. Corti, Cross-neutralization of SARS-CoV-2 by a human monoclonal SARS-CoV antibody. Nature 583, 290-295 (2020). doi:10.1038/s41586-020-2349-y Medline

87. R. Yang, B. Huang, R. A, W. Li, W. Wang, Y. Deng, W. Tan, Development and effectiveness of pseudotyped SARS-CoV-2 system as determined by neutralizing efficiency and entry inhibition test in vitro. Biosaf. Health 2, 226-231 (2020). doi:10.1016/i.bsheal.2020.08.004 Medline

88. National Research Council Canada, "HEK293SF-3F6 and HEK293-6E expression platforms (L-10894 / 11266 / 11565)" (2019); https://nrc.canada.ca/en/research-development/intellectual-propertylicensing/hek293sf-3f6-hek293-6e-expression-platforms-l-10894-11266-11565.

89. P. A. Harris, R. Taylor, R. Thielke, J. Payne, N. Gonzalez, J. G. Conde, Research electronic data capture (REDCap)-A metadata-driven methodology and workflow process for providing translational research informatics support. J. Biomed. Inform. 42, 377-381 (2009). doi:10.1016/j.jbi.2008.08.010 Medline

90. P. A. Harris, R. Taylor, B. L. Minor, V. Elliott, M. Fernandez, L. O'Neal, L. McLeod, G. Delacqua, F. Delacqua, J. Kirby, S. N. Duda, REDCap Consortium, The REDCap consortium: Building an international community of software platform partners. J. Biomed. Inform. 95, 103208 (2019). doi:10.1016/j.jbi.2019.103208 Medline

91. K. H. D. Crawford, R. Eguia, A. S. Dingens, A. N. Loes, K. D. Malone, C. R. Wolf, H. Y. Chu, M. A. Tortorici, D. Veesler, M. Murphy, D. Pettie, N. P. King, A. B. Balazs, J. D. Bloom, Protocol and Reagents for Pseudotyping Lentiviral Particles with SARSCoV-2 Spike Protein for Neutralization Assays. Viruses 12, 513 (2020). doi:10.3390/v12050513 Medline

92. C. L. Hsieh, J. A. Goldsmith, J. M. Schaub, A. M. DiVenere, H.-C. Kuo, K. Javanmardi, K. C. Le, D. Wrapp, A. G. Lee, Y. Liu, C.-W. Chou, P. O. Byrne, C. K. Hjorth, N. V. Johnson, J. Ludes-Meyers, A. W. Nguyen, J. Park, N. Wang, D. Amengor, J. J. Lavinder, G. C. Ippolito, J. A. Maynard, I. J. Finkelstein, J. S. McLellan, Structure-based design of prefusion-stabilized SARS-CoV-2 spikes. Science 369, 1501-1505 (2020). doi:10.1126/science.abd0826 Medline

93. O. Dintwe, S. Rohith, K. V. Schwedhelm, M. J. McElrath, E. Andersen-Nissen, S. C. De Rosa, OMIP-056: Evaluation of Human Conventional T Cells, DonorUnrestricted T Cells, and NK Cells Including Memory Phenotype by Intracellular Cytokine Staining. Cytometry A 95, 722-725 (2019). doi:10.1002/cyto.a.23753 Medline

94. H. Horton, E. P. Thomas, J. A. Stucky, I. Frank, Z. Moodie, Y. Huang, Y.-L. Chiu, M. J. McElrath, S. C. De Rosa, Optimization and validation of an 8-color intracellular cytokine staining (ICS) assay to quantify antigen-specific T cells induced by vaccination. J. Immunol. Methods 323, 39-54 (2007). doi:10.1016/i.jim.2007.03.002 Medline

95. X. Wu, Z.-Y. Yang, Y. Li, C.-M. Hogerkorp, W. R. Schief, M. S. Seaman, T. Zhou, S. D. Schmidt, L. Wu, L. Xu, N. S. Longo, K. McKee, S. O'Dell, M. K. Louder, D. L. Wycuff, Y. Feng, M. Nason, N. Doria-Rose, M. Connors, P. D. Kwong, M. Roederer, R. T. Wyatt, G. J. Nabel, J. R. Mascola, Rational design of envelope identifies broadly neutralizing human monoclonal antibodies to HIV-1. Science 329, 856861 (2010). doi:10.1126/science.1187659 Medline

\section{ACKNOWLEDGMENTS}

We thank the study participants for their dedication to this project, Trevor Bedford for assistance with the selection of spike mutations to include, Laura Richert Spuhler for assistance with figure preparation, Todd Haight and the Seattle Vaccine Unit specimen processing lab and staff for their service. This work was conducted under Fred Hutchinson Cancer Research Center Institutional Review Board IR10440 and IR5567. Funding: This work was supported by generous 
donations to Fred Hutch COVID-19 Research Fund, and to MJM from the Paul G. Allen Family Foundation, the Joel D. Meyers Endowed Chair, and NIAID UM1 AI068618-14S1, 2UM1 AI069481-15, and UM1A057266-S1, and Sanofi Pasteur to Z.M. Author contributions: Conceptualization, M.J.M., A.T.M., and L.S.; Investigation, Y-H. W., E.S., M.L., V.R., K.W.C., Z.M., M.N., L.J.H., A.J.M., M.J, J.F, G.M., H.G., and A.T.M; Writing - Original Draft, A.T.M., and L.S.; Writing - Review \& Editing, A.T.M., L.S., M.J.M., and E.S.; Funding Acquisition, L.S. and M.J.M;

Resources, M.J.M., J.C., A.F.; Supervision, A.T.M. Competing interests: L.S. and A.T.M. have filed a provisional patent application on the CV1, CV30 and CV2-75 SARS-CoV-2 specific monoclonal antibodies. L.S., A.T.M., and A.F. have filed a provisional patent application on the CV3-1 SARS-CoV-2 specific monoclonal antibody. All other authors declare no competing interests. Data and materials availability: All data are available in the manuscript or the supplementary materials. The accession numbers for the sequences of the CV3-1 and CV2-75 heavy and light chain variable regions have been deposited in GenBank: MW681558, MW681586, MW681758 and MW68175. The expression plasmids for the mAbs in this study are derived from the pTT3 vector which requires a license from the National Research Council Canada (88). This work is licensed under a Creative Commons Attribution 4.0 International (CC BY 4.0) license, which permits unrestricted use, distribution, and reproduction in any medium, provided the original work is properly cited. To view a copy of this license, visit https://creativecommons.org/licenses/by/4.0/. This license does not apply to figures/photos/artwork or other content included in the article that is credited to a third party; obtain authorization from the rights holder before using such material.

\section{SUPPLEMENTARY MATERIALS}

science. sciencemag.org/cgi/content/full/science.abg9175/DC1

Materials and Methods

Figs. S1 to S8

Tables S1 to S4

References (89-95)

MDAR Reproducibility Checklist

4 February 2021; accepted 19 March 2021

Published online 25 March 2021

10.1126/science.abg9175 


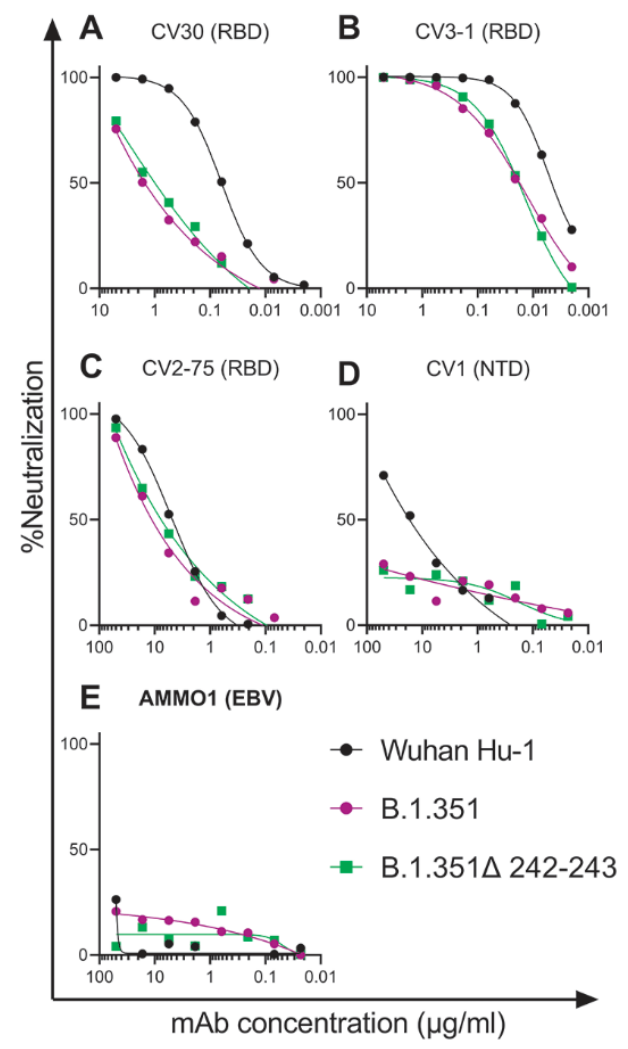

Fig. 1. B.1.351 variants show decreased susceptibility to neutralizing monoclonal antibodies. (A to E) The ability of the indicated monoclonal antibodies (mAbs) to neutralize Wuhan-Hu-1, B.1.351 and B.1.351 $\triangle 242-243$ pseudovirus infectivity in 293T-hACE2 cells was measured as indicated. The epitope specificity of each $\mathrm{mAb}$ is shown in parentheses (RBD: receptor binding domain; NTD: N-terminal domain; EBV: Epstein-Barr virus). Data points represent the mean of two technical replicates. Data are representative of two independent experiments. 

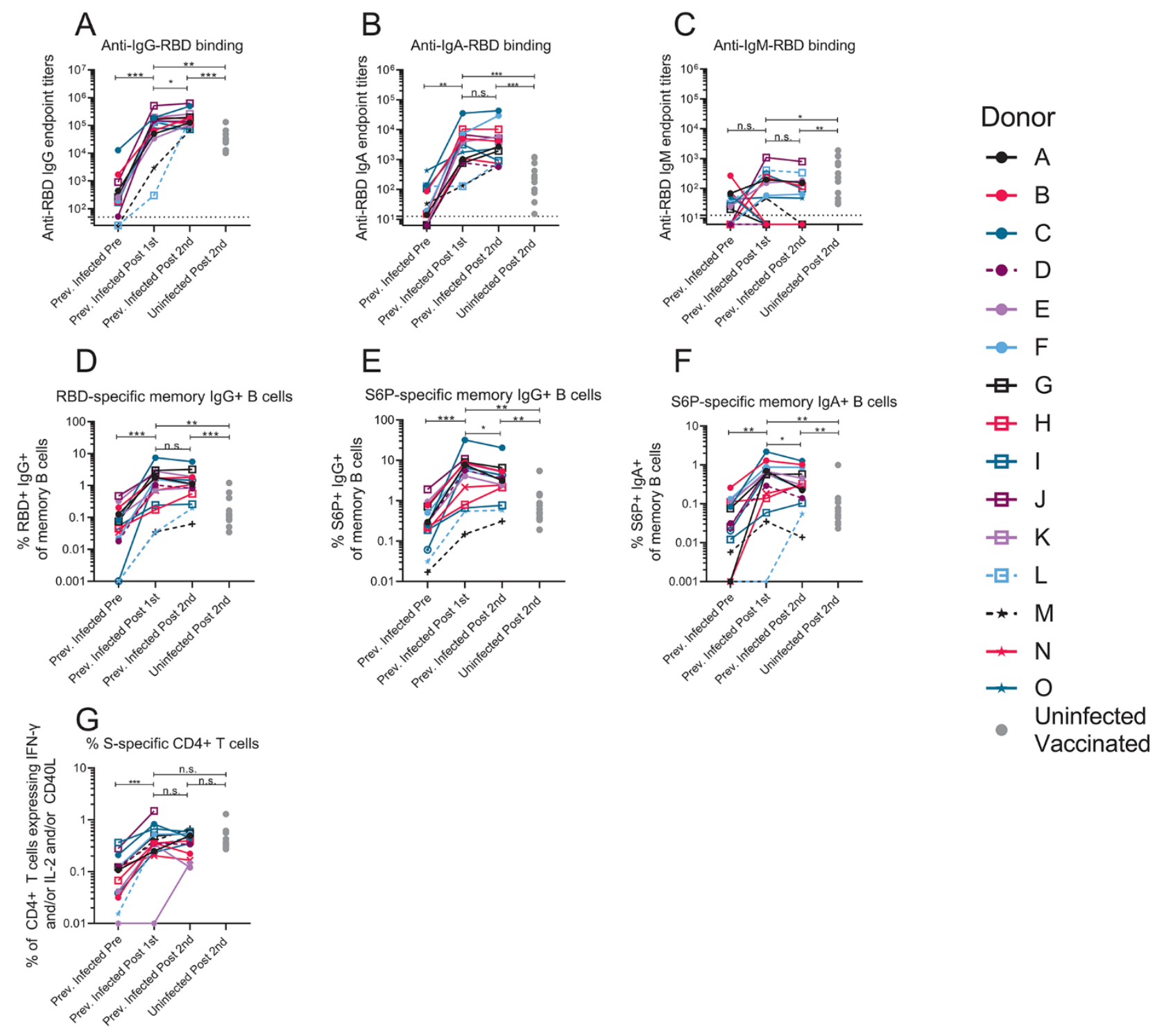

Fig. 2. A single dose of a spike-derived mRNA vaccine elicits a strong recall response. $\lg (A), \lg A$ (B) and $\operatorname{lgM}(\mathrm{C})$ end-point antibody titers specific to the receptor binding domain of the Wuhan-Hu-1 variant were measured in serum collected from donors previously infected with SARS-CoV-2 before and after one or two immunizations with the Pfizer/BioNTech or Moderna mRNA vaccines by ELISA, as indicated. Endpoint titers measured in sera from uninfected donors following two vaccine doses are shown for comparison (gray dots). (D) Frequency of Wuhan-Hu-1 RBD-specific IgG+ memory B cells (live, IgD', CD19+, CD20, CD3, CD14, CD56', singlet, lymphocytes) in PBMC from previously infected donors was measured before and after one or two immunizations. The frequency of S6P-specific lgG ${ }^{+}$ $(E)$ and $\lg \mathrm{A}^{+}(\mathrm{F})$ memory $\mathrm{B}$ cells in PBMC previously infected donors were measured before and after one or two immunizations. The frequency of memory $B$ cells from uninfected donors following two vaccine doses are shown for comparison in D-F (gray dots). (G) The frequency of S-specific CD4+ T cells expressing IFN-y and/or IL-2 and/or CD4OL in PBMC from previously infected donors was measured before and after one or two immunizations. The frequency of S-specific CD4+ T cells in PBMC from uninfected donors following two vaccine doses are shown for comparison (gray dots). Experiments were performed once. Significant differences in infected donors before or after vaccination (A-D) or between pseudoviruses (E) were determined using a Wilcoxon signed rank test $\left({ }^{*} p<0.05,{ }^{* *} p<0.01\right.$ and ${ }^{* *} p<0.001$ ). Significant differences between previously infected and uninfected donors (A-D) were determined using a Wilcoxon rank sum test $\left({ }^{*} p<0.05\right.$, ${ }^{* *} p<0.01$ and $\left.{ }^{* *} p<0.001\right)$. 
A

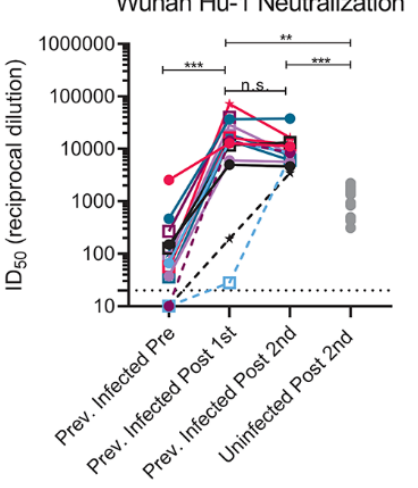

C

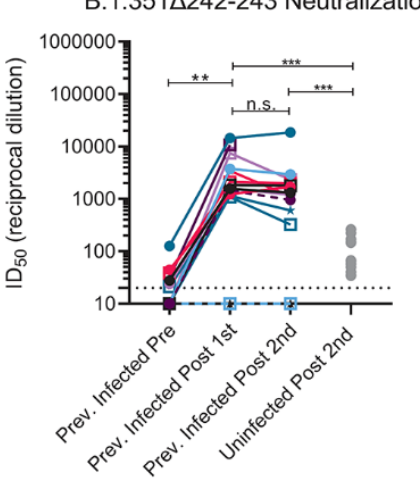

E

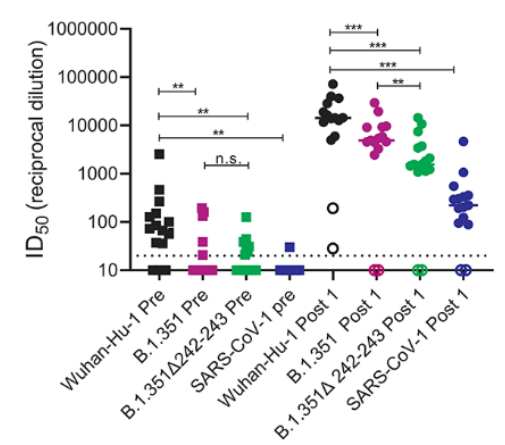

B
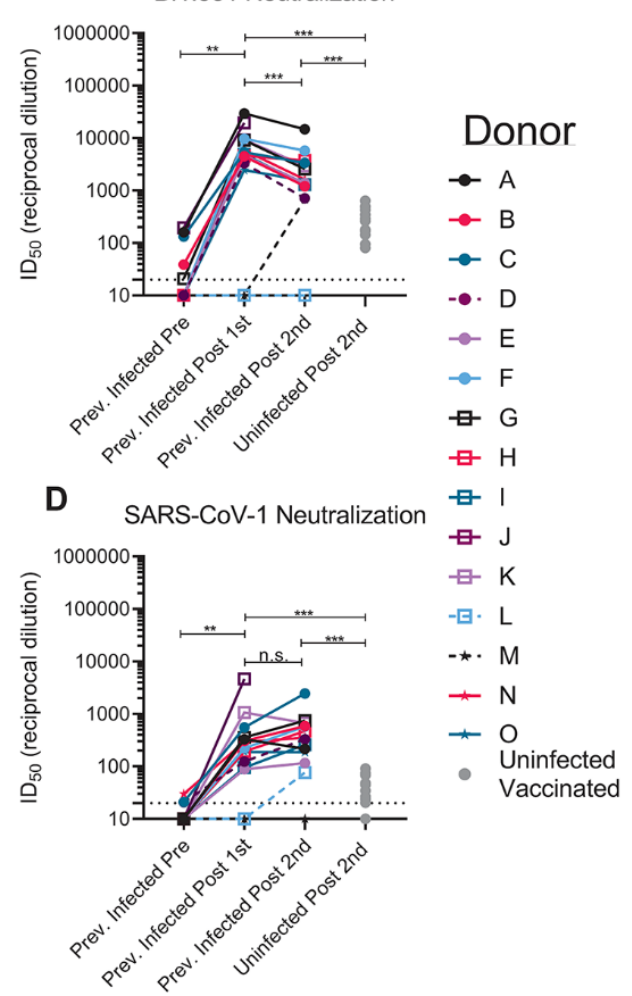

$\mathbf{F}$

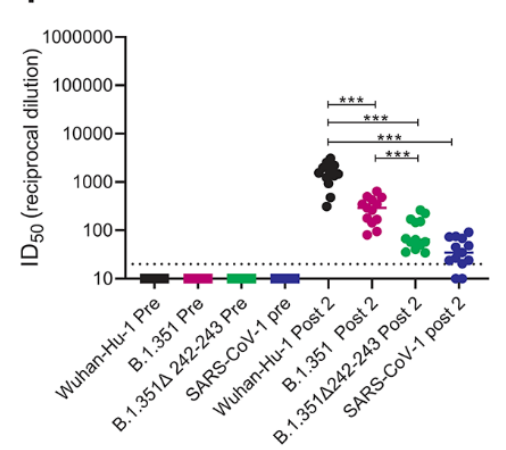

Donor

$\rightarrow A$

$\rightarrow B$

$\rightarrow C$

- D

$\because E$

$\rightarrow F$

\# $\mathrm{G}$

ष $\mathrm{H}$

世 J

曰 $\mathrm{K}$

$+\mathrm{N}$

Uninfected

Vaccinated

Uninfected Vaccinated
Fig. 3. Pre-existing SARS-CoV-2 neutralizing antibody responses are boosted by a single dose of a spikederived mRNA vaccine. The serum dilution resulting in 50\% neutralization $\left(\mathrm{ID}_{50}\right)$ of $(\mathrm{A})$ Wuhan-Hu1, (B) B.1.351, (C) B.1.351 $\triangle 242-243$, and (D) SARS-CoV-1 pseudoviruses was measured in recovered COVID-19 donors prior to and following a one or two immunizations with the Pfizer/BioNTech or Moderna vaccines, and in uninfected donors following two vaccine doses as indicated. Data points between previously infected donors who were symptomatic and asymptomatic are connected by solid and dashed lines, respectively in A-D. (E) Serum dilution resulting in 50\% neutralization (ID 50 ) from recovered donors prior to (squares) and following a single immunization (circles) with the Pfizer/BioNTech or Moderna vaccines against Wuhan-Hu-1, B.1.351, B.1.351 $\triangle 242-243$ and SARS-CoV-1 pseudoviruses as indicated. Previously infected donors who were asymptomatic, negative for anti-lgG RBD antibodies, and RBD-specific IgG+ memory $B$ cells prior to vaccination are shown as open circles. (F) Neutralizing potency $\left(\mathrm{ID}_{50}\right)$ of serum from uninfected donors following two immunizations with the Pfizer/BioNTech or Moderna vaccines against the indicated pseudoviruses. Each data point represents a different donor and the horizonal bars represent the medians in $\mathrm{E}$ and $\mathrm{F}$. The dashed lines demarcate the lowest serum dilutions tested. Experiments were performed once. Significant differences in infected donors before or after vaccination, or from the same timepoint against different variants $\left({ }^{*} p<0.05,{ }^{* *} p<0.01\right.$ and $\left.{ }^{* *} p<0.001\right)$ were determined using a Wilcoxon signed rank test. Significant differences between previously infected and uninfected donors $\left({ }^{*} p<0.05,{ }^{* *} p<0.01\right.$ and $\left.{ }^{* * *} p<0.001\right)$ were determined using a Wilcoxon rank sum test. 

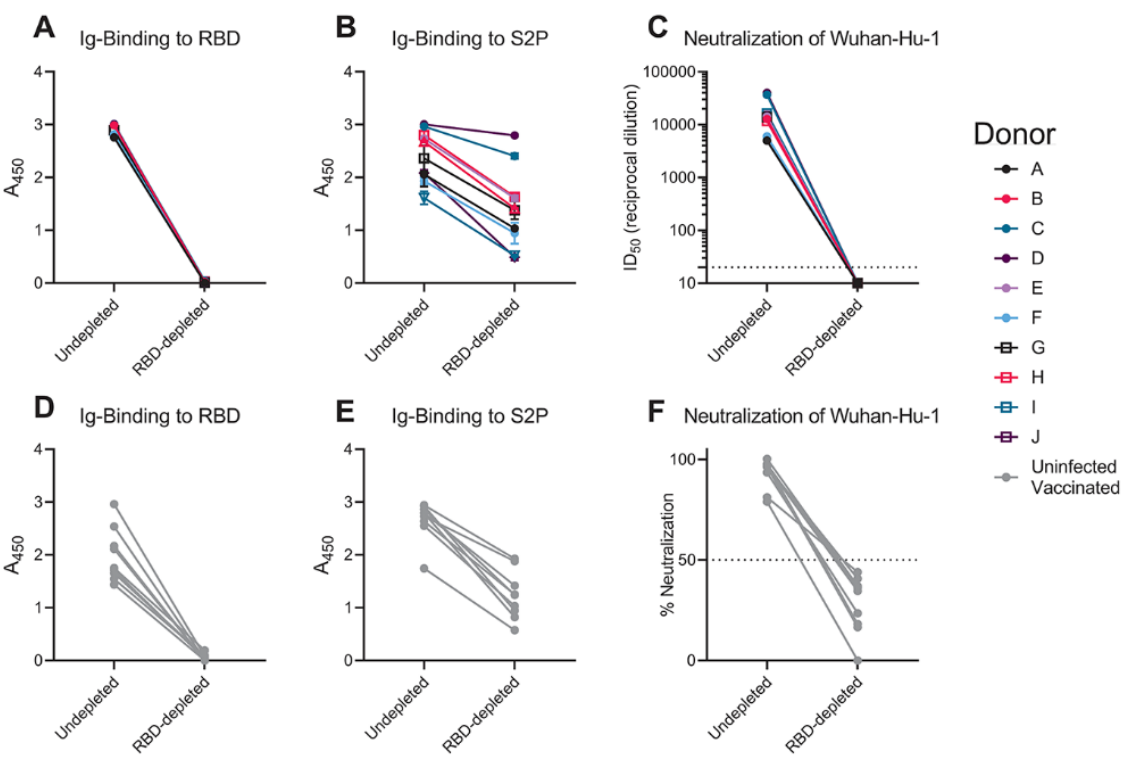

Fig. 4. Vaccine-elicited neutralizing antibodies target the RBD. RBDbinding antibodies were adsorbed from sera from previously infected donors after receiving a single vaccine dose, or from uninfected donors after receiving two vaccine doses using Wuhan-Hu-1 RBD immobilized to magnetic beads. Antibody binding in undepleted or RBD-depleted serum from previously infected donors was measured to RBD at a 1:500 dilution (A), and S2P at a 1:4500 dilution (B) by ELISA as indicated. (C) The serum dilution resulting in 50\% neutralization (ID50) of the Wuhan-Hu-1 pseudovirus was measured in undepleted or RBDdepleted of serum from the previously SARS-CoV-2 infected donors in $A$ and $\mathrm{B}$. Antibody binding in undepleted and RBD-depleted and sera from uninfected vaccinated donors was measured to RBD at a 1:500 dilution (D), and S2P at a 1:500 dilution (E) by ELISA. (F) The percent neutralization of a 1:120 dilution of undepleted or RBD-depleted of serum from the donors in $D$ and $E$ was measured against the WuhanHu-1 rxipseudovirus. Experiments were performed once. 